\title{
Tek Tohum Nesli Seleksiyon Yöntemi ile Geliştirilen Aspir (Carthamus tinctorius L.) Hatlarının Tarımsal ve Teknolojik Özelliklerinin Belirlenmesi
}

\author{
Ali ŞENATEŞ1 (D), Sabri ERBAŞ² (D) \\ 1,2Isparta Uygulamalı Bilimler Üniversitesi, Ziraat Fakültesi, Tarla Bitkileri Bölümü, 32260, Isparta, Türkiye
}

(Alınış / Received: 12.11.2019, Kabul / Accepted: 06.01.2020, Online Yayınlanma / Published Online: 20.04.2020)

Anahtar Kelimeler

Aspir,

Carthamus tinctorius,

Hat geliştirme,

Tek tohum nesli,

Verim ve kalite
Özet: Bu çalışma, Isparta Uygulamalı Bilimler Üniversitesi Ziraat Fakültesi Tarla Bitkileri Bölümü'nde 2016 yllında tesadüf blokları deneme desenine göre 3 tekerrürlü olarak yürütülmüștür. Gelendost-2 (GE) hattı ile Centennial (CE), Montola 2000 (MO) ve W6 9822 (W6) çeşitlerinin melezlemesinden elde edilerek $\mathrm{F}_{8}$ generasyonuna kadar tek tohum nesli seleksiyon yöntemi ile ulaştırılan 68 hat (20 adet GE $\times \mathrm{CE}, 28$ adet $\mathrm{GE} \times \mathrm{MO}$ ve 20 adet $\mathrm{GE} \times \mathrm{W} 6$ ) ve aspir genotipleri (Gelendost-2, Montola 2000, W6 9822, Dinçer 5-18-1, Remzibey-05, Balcı, Linas ve Olas) materyal olarak kullanılmıştır. Sonuçlara göre; 1000 tane ağırlığı, tohum verimi, yağ oranı ve yağ veriminin sırasıyla $30.2-51.0$ g, 30.2-252.6 kg/da, \% 25.135.4 ve $10.0-77.2 \mathrm{~kg} /$ da arasında değiştiği görülmüsstür. GECE-11 ve 12 hatlarının 1000 tane ağırlı̆̆l, GEMO-10 ve 19 nolu hatlarının tohum verimi, GEMO-1, 20, 28, GEW6-16, 20 ve GECE-4, 8, 9, 12 nolu hatların yağ oranı, GEMO-10, 19, 28 ve GEW6-20 nolu hatlarının ise yağ verimi açısından ebeveynler ve çeşitlere göre daha üstün oldukları belirlenmiștir. Sonuç olarak 4 adet verim tipi (GECE-11, 12 ve GEMO-10,19), 11 adet yağ tipi (GEMO-1, 10, 19, 20, 28, GEW6-16, 20 ve GECE-4, 8, 9, 12), 2 adet oleik tipi (GEMO-3 ve GEMO-23), 1 adet linoleik tipi (GECE-7) olmak üzere 15 hat bir sonraki generasyona aktarılmıștır.

\section{Determination of Agricultural and Technological Characters of Safflower (Carthamus tinctorius L.) Lines Developed by Single Seed Descent Selection Methods}

\section{Keywords}

Safflower,

Carthamus tinctorius,

Lines development,

Single seed descent,

Yield and quality

\begin{abstract}
This study was conducted in 2016 as 3 replications at randomized blocks design at Department of Field Crops, Faculty of Agriculture, Isparta Applied Sciences University. Total of 68 lines $(20$ progenies from GE $\times$ CE, 20 from GE $\times$ W6 and 28 from $\mathrm{GE} \times \mathrm{MO}$ ) were selected with single seed descent methods up to $\mathrm{F}_{8}$ generation. These lines derived from hybridization of Gelendost-2 and Centennial, Montola 2000 and W6 9822. Standard genotypes (Gelendost-2, Montola 2000, W6 9822, Dinçer 5-18-1, Remzibey-05, Balcı, Linas and Olas) were also used along with the alove lines as plant materials. According to the results; 1000 seed weight, seed yield, oil content and oil yield were varied between 30.2-51.0 g, 30.2-252.6 $\mathrm{kg} / \mathrm{da}, 25.1-35.4 \%$ and 10.0-77.2 $\mathrm{kg} / \mathrm{da}$, respectively. GECE-11, 12 had higher 1000seed weight, GEMO-10, 19 had higher seed yield, GEMO-1, 20, 28, GEW6-16, 20 and GECE-4, 8, 9, 12 had higher oil content, GEMO-10, 19, 28 and GEW6-20 had higher oil yield than cultivars. As a result, 4 yield types (GECE-11, 12 and GEMO10, 19), 11 oil types (GEMO-1, 10, 19, 20, 28, GEW6-16, 20 and GECE-4, 8, 9, 12), 2 oleic types (GEMO-3 and GEMO-23), 1 linoleic type (GECE-7) 15 lines are transferred to the next generation.
\end{abstract}

\section{Giriș}

Türkiye, uzun yıllardır yağlı tohumlar ve bitkisel yağlar ticaretinde net ithalatçı $\left(\begin{array}{lll}\% & 70\end{array}\right)$ ülkeler arasında yer almakta ve birçok tarımsal üründeki yeterli üretimine karşın özellikle yağlı tohumlar ve bitkisel yağlar üretiminde giderek artan nüfusa ve yağların kullanım alanlarının genişlemesine paralel olarak dış ticaret açığı gittikçe büyümekte olup petrol ve ürünlerinden sonra en büyük ikinci ithalat kalemi durumundadır. Türkiye İstatistik Kurumu'nun (TUIK) dış ticaret verilerine göre, Türkiye 2018 yılında 3.7 
milyon ton yağlı tohum (1.6 milyar \$), 1.3 milyon ton ham yă̆ (1.1 milyar \$), 3.5 milyon ton küspe (837 milyon \$) ve olmak üzere 3.5 milyar \$ değerinde toplam 8.5 milyon ton bitkisel yağ, yağlı tohum ve küspe ithal etmiştir [1]. Aspir bitkisi geniş alanlarda ticari olarak yetiştirilmesi durumunda, hem üretici ve hem de sanayici isteklerine cevap verebilecek bir potansiyele ulaşması mümkündür. Kurak ve tuzlu topraklarda ve nispeten soğuk bölgelerde ve yüksek bir tolerans gösteren aspir ülkemizin kuru tarım yapılan alanlarında başarılı bir şekilde üretilebilir [2]. Özellikle karasal iklimim hüküm sürdüğü Orta, Doğu ve Geçit Bölgeleri gibi kuru tarım bölgelerinde tahıllarla münavebeli olarak en azından nadas yılında aspir ekimi yapılabilir. Ancak kültürü yapılan aspir çeşitlerinin tohum verimi (Türkiye ortalaması kuru koşullarda $150 \mathrm{~kg} /$ da ve sulu koşullarda 200 $\mathrm{kg} / \mathrm{da}^{\prime}$ dır) ve yağ oranı (\%25-33) düşüktür [3]. Aspir tohum veriminin ve yağ oranının diğer yağ bitkilerine göre nispeten düşük kalması, dünyada ve Türkiye'de tarımının istenen seviyede gelişmesinin önüne geçmektedir.

Aspir ıslahının hedefi; tohum/yağ verimi ve kalitesi yüksek, olumsuz çevre koşulları ile hastalık ve zararlılara dayanıklı yüksek adaptasyon ve stabilite gösteren hibrit çeşitler geliştirmektir [4]. Islah amaçları doğrultusunda, geliştirilen aspir çeşit ve hatlarının farklı çevre koşullarında stabil bir üretime izin verecek șekilde adaptasyon yeteneğinin ve verim performansının yüksek olması gerekir. Genetik çeşitlilik barındıran populasyonlardan veya introdüksiyon materyallerinden melezlemeye başvurmadan basit toplu veya teksel seleksiyon yöntemleriyle çok sayıda saf hat elde edilerek kolaylıkla çeşit geliştirilebilir. Türkiye'deki ticari aspir çeşitlerinin 2019 yılında Dinçer 5-118 ve Montola 2000 melez populasyonundan geliştirilen ve tescil edilen Olein, Safir ve Zirkon çeşitleri dişında tamamı (Yenice 5-38, Dinçer 5-11-8, Remzibey-05, Balcı, Linas, Olas ve Asol gibi) introdüksiyon materyallerinden seleksiyon yapılarak geliștirilmişlerdir. Oysa dünyada ticari değeri yüksek aspir çeşitleri yaygın olarak melezleme ıslahı ile geliştirilmiş olan çeşitlerdir [4] ve aspirin ıslah amaçları doğrultusunda ülkemizde de bu sayının artırılması gereklidir.

Bu çalışmada; Gelendost 2 (GE) hattı ile Centennial (CE), Montola 2000 (MO) ve W6 9822 (W6) çeşitlerinin melezlemesinden elde edilen $\mathrm{F}_{8}$ generasyonu (GE $\times$ CE melezi 20 hat, GE $\times$ MO melezi 28 hat ve GE×W6 melezi 20 hat) toplam 68 hat ebeveynleri ve diğer standart aspir çeşitleri (Dinçer 5-18-1, Remzibey-05, Balcı, Linas, Olas) ile agronomik ve kalite özellikleri bakımından karşılaştırılmıştır.

\section{Materyal ve Metot}

Bu çalışma 2016 yılında Isparta Uygulamalı Bilimler Üniversitesi Ziraat Fakültesi Tarla Bitkileri Bölümü yürütülmüştür. Çalışmada materyal olarak 2008 yılında sentetik kimyasal erkek kısırlık oluşturularak melezlenen ve $\mathrm{F}_{8}$ generasyonuna kadar tek tohum soy nesli seleksiyon yöntemi ile ulaştırılan "Gelendost-2 $\times$ Centennial" melezi 20 hat,"Gelendost- $2 \times$ Montola 2000" melezi 28 hat ve "Gelendost-2 × W6 9822" melezi 20 hat ve 6 adet standart çeşit (Dinçer 5-11-8, Centennial, Remzibey-05, Balcı, Linas, Olas) materyal olarak kullanılmıștır. Ana ve baba ebeveynlerin melezleme ve $\mathrm{F}_{8}$ gererasyonuna kadar süren seleksiyon aşamaları Şekil 1'de sunulmuştur.

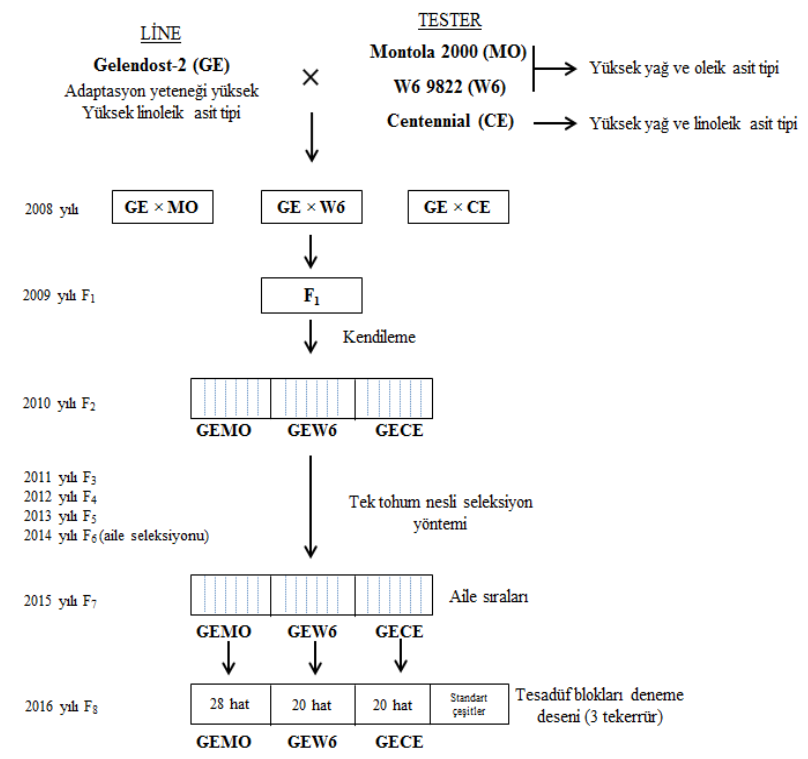

Şekil 1. Materyallerin melezleme ve seleksiyon aşamaları

Tarla denemelerinin kurulduğu 2016 yllına ilişkin iklim verileri incelendiğinde, vejetasyon döneminde (Mart-Ağustos) genel olarak aspir bitkisinin normal büyüme ve gelişmesini olumsuz yönde etkileyecek sıcaklıklar yaşanmamış, yine özellikle Nisan-Haziran ayları arasında aspir bitkilerinin ihtiyacı olan su yağışlarla sağlanmıştır (Tablo 1.). $\mathrm{Bu}$ nedenle, denemede sulama yapılmamıș, bu dönemde (toplam $147.8 \mathrm{~mm}$ ) düşen yağışlar sayesinde bitkilerin çıkış, rozet ve sapa kalkma dönemleri başarılı bir şekilde atlatılmıştır. Yine çiçeklenme dönemi sonrasında aralıklarla düşen yağışlar döllenme sonrası tane dolumuna katkı sağlamıştır. Diğer taraftan olgunlaşma döneminde düşen yağışlar bitkilerin hasat ve harmanına herhangi bir olumsuzluk oluşturmamıştır. Araştırma alanının toprak özellikleri Rowell [5], tarafından önerilen metoda bağlı olarak yapılmıştır. Toprak tekstürü bakımından killi-tınlı, organik madde içeriği Walkley-Black metodu ile \% 1.1, kireç içeriği Schiebler kalsimetre ile 7.20 (\%), tuz oranı \% 0.38, alınabilir fosfor 3.9 $\mathrm{mg} / \mathrm{kg}$, alınabilir potasyum $1 \mathrm{~N} \mathrm{NH}_{4} \mathrm{OAc}$ da 119.0 $\mathrm{mg} / \mathrm{kg}$ olduğu belirlenmiştir. Diğer taraftan toprak pH'sı hafif alkali ( $\mathrm{pH}$ 7.5) yapıda olduğu tespit edilmiştir. Aspir, diğer birçok tarla bitkisine göre daha az toprak seçiciliği olan bir bitkidir. Bu yönüyle deneme alanı toprağı her ne kadar alkali, ağır yapılı ve organik maddesi düşük de olsa aspir tarımı için yeterlidir. 
Tablo 1. Isparta ilinin 2016 yılı Isparta iline ait aylık ortalama yağıș, sıcaklık ve nem değerleri [8]

\begin{tabular}{lcccccc}
\hline Aylar & \multicolumn{1}{c}{ Yağıș $\left(\mathrm{L} / \mathrm{m}^{2}\right)$} & \multicolumn{3}{c}{ Sicaklık $\left({ }^{\circ} \mathrm{C}\right)$} & \multicolumn{2}{c}{ Nem (\%) } \\
\cline { 2 - 7 } & $1950-2015$ & 2016 & $1950-2015$ & 2016 & $1950-2015$ & 2016 \\
\hline Ocak & 73.6 & 96.8 & 1.9 & 1.6 & 73.2 & 71.6 \\
Şubat & 64.0 & 33.3 & 2.9 & 7.1 & 70.2 & 68.0 \\
Mart & 55.3 & 59.9 & 6.2 & 7.7 & 65.3 & 60.7 \\
Nisan & 55.3 & 47.8 & 10.8 & 14.5 & 61.0 & 48.5 \\
Mayıs & 52.3 & 87.6 & 15.6 & 15.1 & 57.4 & 61.5 \\
Haziran & 30.6 & 12.4 & 20.2 & 22.0 & 51.2 & 43.9 \\
Temmuz & 14.6 & 25.7 & 23.7 & 25.4 & 45.3 & 40.8 \\
Ağustos & 11.7 & 45.4 & 23.2 & 24.7 & 46.4 & 47.6 \\
\hline
\end{tabular}

Her üç popülasyona ait hatlar ve çeşitler $45 \times 15 \mathrm{~cm}$ ekim normunda $5 \mathrm{~m}$ uzunluğunda 3 sıra olacak șekilde tesadüf blokları deneme desenine göre üç tekerrürlü olarak 24.03.2016 tarihinde ekilmișlerdir. Ekimle birlikte deneme alanına taban gübresi olarak $6 \mathrm{~kg}$ saf fosfor olacak $\left(\mathrm{P}_{2} \mathrm{O}_{5}\right)$ şekilde diamonyum fosfat ( $\% 18 \mathrm{~N}, \% 46 \mathrm{P}_{2} \mathrm{O}_{5}$ ) ve üst gübre olarak $8 \mathrm{~kg}$ saf azot $(\mathrm{N})$ olacak şekilde amonyum nitrat (\%33) gübresi atılmıştır. Yağışlar aspirin çıkış, büyüme ve gelişmesi için yeterli olduğundan denemede sulama yapılmamıştır. Olgunlaşma ile birlikte parsellerde rastgele seçilen 10 bitkide bazı önemli tarımsal [bitki boyu (cm), dal sayısı (adet/bitki), tabla sayısı (adet/bitki), tabla çapı (mm), hasat indeksi (\%), 1000 tane ağırlığ $(\mathrm{g})$, tohum ve yağ verimi $(\mathrm{kg} / \mathrm{da})]$ ve kalite [kabuk oranı (\%), yağ oranı (\%) ve yağ asitleri kompozisyonu (\%)] özellikleri belirlenmiștir. Çeșit ve hatların yağ analizleri, Nükleer Manyetik Rezonans (NMR) cihazında \% olarak okutularak saptanmıştır. Tohumlar $70{ }^{\circ} \mathrm{C}$ ayarlı etüvde 48 saat bekletilerek nemi uçurulup 2'şer g tartılmış ve NMR cihazında her parselde 3 okuma yapılarak \% yağ oranı ortalaması hesaplanmıștır. Yağ asitleri kompozisyonu ise alev iyonlaşma detektöre (FID) sahip gaz kromotografisi (Shimadzu GC-2025) cihazında yapılmıştır. 2 g kurutulmuş ögütülmüş aspir tohumu n-hekzan ile soğuk ekstraksiyona tutulmuş ve solvent karıșımı uçurulduktan sonra elde edilen ham yağ AOAC [6] tarafindan önerilen yöntemle \%0.5'lik Sodyum Metilat (NaoMe) ile metil esterlerine (FAME) dönüştürmüștür. Yağ asitlerine ilişkin kromatogramlar elde edilerek palmitik (C16:0), stearik (C18:0), oleik (C18:1) ve linoleik (C18:2) yağ asitlerinin \% oranları tespit edilmiștir. GC cihazının çalışma koşulları șu şekildedir; Kolon Teknokroma TR-CN100 (100 m $\times 0.25 \mu \mathrm{m}, 0.20 \mu \mathrm{m})$, enjektör sıcaklığı $250{ }^{\circ} \mathrm{C}$, detektör sıcaklığı $250{ }^{\circ} \mathrm{C}$, akış hızı (psi) 10, taşıyıcı gaz $\mathrm{N}$ ( $40 \mathrm{ml} / \mathrm{dk}$ ), enjektör kapasitesi 1.0pl'dir. Firın sıcaklığ $140^{\circ} C^{\prime}$ de 10 dakika bekledikten sonra $240{ }^{\circ} \mathrm{C}$ 'ye dakikada $3^{\circ} \mathrm{C}$ 'lik artışla ulaşıyor ve bu sıcaklıkta 10 dakika bekliyor. Elde edilen kromotogramlardaki pikler ticari standart yağ asidi metil ester karışımına (Sigma, Supelco ${ }^{\circledR} 37$ Component FAME Mix) göre isimlendirilmiştir. Elde edilen veriler tesadüf blokları deneme desenine göre SAS [7] istatistik paket programında analiz edilmiştir.

\section{Bulgular ve Tartışma}

Aspir genotiplerinin bitki boyu ortalamalarına göre her üç popülasyonda da Gelendost-2 hattı en uzun $(100.7 \mathrm{~cm})$, W6 9822 çeşidi ise en kısa $(64.7 \mathrm{~cm})$ bitki boyuna sahip olduğu gözlenmiștir (Tablo 2, 3, 4). GEMO popülasyonunda GEMO-4, 9, 10 ve 16 ve 27 nolu hatlar ile Balcı çeşidi (Tablo 2), GEW6'da GEW6$5,6,7,8,12,14,16$ ve 18 nolu hatlar ile Balcı çeşidi (Tablo 3), GECE'de GECE-16, 18 ve 19 nolu hatlar ile Balcı, Olas ve Remzibey-05 çeşitleri, W6 9822 çeşidi (Tablo 4) ile aynı istatiksel grupta yer almışlardır. Aspirde makineli hasada uygunluk ve ekonomik bir verim alınması açısından bitki boyunun $55.0-65.0 \mathrm{~cm}$ olması gerektiğini bildirilmiştir [9]. Çalışmamızda sadece W6 9822 genotipi bu sınırlar içerisinde kalmıștır. Diğer taraftan ebeveynlerinden biri olan Gelendost-2 hattı geççi ve uzun boylu bir genotip olduğundan dolayı bu özelliğini hatlara aktardığı düşünülmektedir. Aspirde bitki boyu eklemeli genler tarafından kontrol edildiğinden [10], düşük ve orta düzeyde bir kalıtım derecesi tahminlenmekte [11], bu nedenle yapılan çalışmalarda geniş bir bitki boyu varyasyon rapor edilmektedir. Yapılan çalışmalarda aspirde bitki boyunun 31.7-150.1 cm arasinda değiştiği bildirilmektedir $[2,12-14]$. GEMO populasyonunda W6 9822 genotipi en yüksek dal sayısına ( 7.6 adet/bitki) sahip iken, Linas çeşidi ile 13 hattin $(1,2,4,5,7,8,13,17,19,21,23,24$, ve 28 nolu) en düşük dal sayısına sahip olduğu belirlenmiștir (Tablo 2). GEW6 populasyonunda W6 9822 (7.6 adet/bitki), Montola 2000 (6.7 adet/bitki) ve Centennial (6.5 adet/bitki) genotipleri en yüksek dal sayısına sahip olduğu tespit edilmiștir (Tablo 3). GECE populasyonunda ise GECE-7 (7.8 adet/bitki) genotipinin çeşidinin en yüksek, GECE-2 (4.0 adet/bitki) genotipinin ise en düşük dal sayısına sahip olduğu saptanmıştır (Tablo 4). Aspirde dal sayısı çevre ve genetik faktörlerden etkilenen bir özelliktir. Nitekim aspirde dal sayısı için \% 64.2 oranında kalıtım derecesi tahminlemiştir [15]. Yapılan diğer çalışmalarda aspirde dal sayısının 4.118.9 arasında değiștiği bildirilmiștir [15-17]. 
Tablo 2. Gelendost- $2 \times$ Montola 2000 melezi hatların agronomik ve kalite özellikleri

\begin{tabular}{|c|c|c|c|c|c|c|c|c|c|c|}
\hline & $\begin{array}{l}\text { Bitki } \\
\text { boyu }\end{array}$ & $\begin{array}{c}\text { Dal } \\
\text { sayısı }\end{array}$ & $\begin{array}{l}\text { Tabla } \\
\text { sayısı }\end{array}$ & $\begin{array}{c}\text { Tabla } \\
\text { çapı }\end{array}$ & $\begin{array}{c}1000 \text { tane } \\
\text { ağırlığ }\end{array}$ & $\begin{array}{c}\text { Hasat } \\
\text { indeksi }\end{array}$ & $\begin{array}{l}\text { Tohum } \\
\text { verimi }\end{array}$ & $\begin{array}{c}\text { Kabuk } \\
\text { oranı }\end{array}$ & $\begin{array}{c}\text { Yağ } \\
\text { oranı }\end{array}$ & $\begin{array}{c}\text { Yağ } \\
\text { verimi }\end{array}$ \\
\hline Genotip (F) & $* *$ & $* *$ & $* *$ & $* *$ & $* *$ & $* *$ & $* *$ & $* *$ & $* *$ & $* *$ \\
\hline CV & 5.1 & 8.8 & 5.7 & 5.9 & 5.2 & 8.7 & 14.2 & 2.8 & 2.6 & 14.4 \\
\hline GEMO-1 & $76.8 \mathrm{c}-\mathrm{i}^{1}$ & $4.9 \mathrm{f}-\mathrm{k}$ & $8.81-n$ & $25.8 \mathrm{a}$ & 35.5 h-m & $20.6 \mathrm{~g}-\mathrm{l}$ & $171.2 \mathrm{~g}-\mathrm{l}$ & $44.2 \mathrm{mn}$ & $34.9 \mathrm{ab}$ & $59.7 b-h$ \\
\hline GEMO-2 & $74.4 \mathrm{e}-\mathrm{j}$ & $4.1 \mathrm{k}$ & $7.8 \mathrm{n}-\mathrm{q}$ & $23.4 \mathrm{a}-\mathrm{h}$ & $35.3 \mathrm{i}-\mathrm{n}$ & $24.1 \mathrm{~b}-\mathrm{g}$ & $201.3 \mathrm{~b}-\mathrm{h}$ & $47.8 \mathrm{e}-1$ & $33.2 \mathrm{c}-\mathrm{h}$ & $66.8 \mathrm{a}-\mathrm{f}$ \\
\hline GEMO-3 & $80.2 \mathrm{c}-\mathrm{f}$ & $5.7 c-f$ & $11.9 \mathrm{fg}$ & $21.1 \mathrm{~g}-\mathrm{l}$ & $38.5 c-h$ & $17.9 \mathrm{k}-\mathrm{p}$ & $148.5 \mathrm{k}-\mathrm{o}$ & $49.3 \mathrm{c}-\mathrm{h}$ & 30.0 o-q & $44.5 \mathrm{i}-\mathrm{m}$ \\
\hline GEMO-4 & $71.6 \mathrm{~g}-\mathrm{k}$ & $4.5 \mathrm{l}-\mathrm{k}$ & $10.0 \mathrm{~h}-\mathrm{k}$ & $21.7 \mathrm{~d}-\mathrm{k}$ & $42.5 \mathrm{ab}$ & $21.3 \mathrm{f}-\mathrm{k}$ & $171.6 \mathrm{~g}-\mathrm{l}$ & $52.1 \mathrm{~b}$ & $30.8 \mathrm{j}-\mathrm{o}$ & $53 \mathrm{f}-\mathrm{j}$ \\
\hline GEMO-5 & $75.0 \mathrm{~d}-\mathrm{j}$ & $4.7 \mathrm{~g}-\mathrm{k}$ & 8.9 l-n & 23.9 a-f & 39.6 b-f & $19.5 \mathrm{i}-\mathrm{o}$ & $175.9 \mathrm{~g}-\mathrm{l}$ & $48.9 c-h$ & $31.2 \mathrm{i}-\mathrm{o}$ & $55.0 \mathrm{e}-\mathrm{j}$ \\
\hline GEMO-6 & $79.9 \mathrm{c}-\mathrm{f}$ & $6.2 \mathrm{~b}-\mathrm{d}$ & $14.6 \mathrm{ab}$ & $23.8 \mathrm{a}-\mathrm{f}$ & 39.5 b-f & $25.1 \mathrm{~b}-\mathrm{d}$ & $220.2 \mathrm{a}-\mathrm{f}$ & $47.9 \mathrm{e}-\mathrm{k}$ & 32.0 g-m & 70.6 a-c \\
\hline GEMO-7 & $77.1 \mathrm{c}-\mathrm{i}$ & $4.6 \mathrm{~h}-\mathrm{k}$ & $6.7 \mathrm{qr}$ & $23.4 \mathrm{a}-\mathrm{h}$ & $31.7 n-q$ & $23.0 \mathrm{~b}-\mathrm{i}$ & $155.3 \mathrm{i}-\mathrm{n}$ & $49.1 \mathrm{c}-\mathrm{h}$ & $30.5 \mathrm{~m}-\mathrm{p}$ & $47.3 \mathrm{~h}-\mathrm{l}$ \\
\hline GEMO-8 & $81.3 \mathrm{c}-\mathrm{e}$ & $4.7 \mathrm{~g}-\mathrm{k}$ & $13.7 \mathrm{bd}$ & $22.6 \mathrm{~b}-\mathrm{k}$ & $30.5 p-q$ & 20.1 h-n & $127.2 \mathrm{~m}-\mathrm{q}$ & $50.6 \mathrm{~b}-\mathrm{d}$ & $30.6 \mathrm{k}-\mathrm{o}$ & $39.0 \mathrm{k}-\mathrm{o}$ \\
\hline GEMO-9 & 70.9 h-k & $6.2 \mathrm{~b}-\mathrm{d}$ & $15.1 \mathrm{a}$ & $18.7 \mathrm{l}$ & $36.5 \mathrm{e}-1$ & 20.7 g-l & $145.2 \mathrm{k}-\mathrm{p}$ & $51.0 \mathrm{bc}$ & $28.6 \mathrm{q}$ & 41.4 j-n \\
\hline GEMO-10 & 68.9 j-k & $6.7 \mathrm{~b}$ & $15.4 \mathrm{a}$ & $20.2 \mathrm{k}-\mathrm{l}$ & $36.3 \mathrm{f}-1$ & $20.3 \mathrm{~h}-\mathrm{m}$ & 238.3 a-c & $47.7 \mathrm{f}-\mathrm{l}$ & $32.3 \mathrm{~g}-\mathrm{j}$ & $77.2 \mathrm{a}$ \\
\hline GEMO-11 & $80.0 \mathrm{c}-\mathrm{f}$ & $5.2 \mathrm{e}-\mathrm{j}$ & $8.6 l-n$ & 24.0 a-e & $35.2 \mathrm{i}-\mathrm{n}$ & 20.0 h-n & 153.6 j-o & $47.8 \mathrm{e}-\mathrm{l}$ & $33.3 \mathrm{c}-\mathrm{h}$ & $51.1 \mathrm{~g}-\mathrm{k}$ \\
\hline GEMO-12 & $82.5 \mathrm{~cd}$ & $5.5 \mathrm{~d}-\mathrm{h}$ & $10.6 \mathrm{~h}-\mathrm{j}$ & 20.6 i-l & $42.1 \mathrm{a}-\mathrm{c}$ & 20.1 h-n & $94.0 \mathrm{q}-\mathrm{t}$ & $57.9 \mathrm{a}$ & $30.5 \mathrm{~m}-\mathrm{p}$ & $28.7 n-q$ \\
\hline GEMO-13 & $76.8 \mathrm{c}-\mathrm{i}$ & $4.6 \mathrm{~h}-\mathrm{k}$ & $10.9 \mathrm{gh}$ & $24.2 \mathrm{a}-\mathrm{d}$ & $38.4 \mathrm{c}-\mathrm{h}$ & $26.1 \mathrm{ab}$ & $185.3 \mathrm{e}-\mathrm{k}$ & $49.5 b-h$ & $30.1 \mathrm{n}-\mathrm{q}$ & $55.8 \mathrm{~d}-\mathrm{i}$ \\
\hline GEMO-14 & $82.2 \mathrm{c}-\mathrm{e}$ & $5.5 \mathrm{~d}-\mathrm{h}$ & $8.1 \mathrm{n}-\mathrm{p}$ & $25.1 \mathrm{ab}$ & $30.2 \mathrm{q}$ & $23.1 \mathrm{~b}-\mathrm{i}$ & $210.0 \mathrm{a}-\mathrm{g}$ & $47.0 \mathrm{~h}-\mathrm{l}$ & $32.4 \mathrm{e}-\mathrm{j}$ & 68.0 a-e \\
\hline GEMO-15 & $81.7 \mathrm{c}-\mathrm{e}$ & $5.2 \mathrm{e}-\mathrm{i}$ & $9.4 \mathrm{k}-\mathrm{m}$ & $23.7 \mathrm{a}-\mathrm{g}$ & 34.2 j-o & 19.3 j-o & $181.2 \mathrm{f}-\mathrm{l}$ & $5 \mathrm{~g}-\mathrm{l}$ & $32.5 \mathrm{e}-\mathrm{i}$ & $58.8 \mathrm{c}-\mathrm{h}$ \\
\hline GEMO-16 & $.6 \mathrm{~g}-\mathrm{k}$ & $5.4 \mathrm{~d}-\mathrm{i}$ & 7.2 o-r & $22.7 \mathrm{~b}-\mathrm{k}$ & $36.9 \mathrm{e}-1$ & $28.3 \mathrm{a}$ & $197.7 \mathrm{c}-\mathrm{i}$ & & $32.3 \mathrm{~g}-\mathrm{j}$ & $63.7 \mathrm{a}-\mathrm{g}$ \\
\hline GEMO-17 & $92.8 \mathrm{~b}$ & $4.8 \mathrm{f}-\mathrm{k}$ & $8.81-n$ & $21.4 \mathrm{e}-\mathrm{k}$ & 32.9 l-q & 19.6 i-o & $252.6 \mathrm{a}$ & $49.1 \mathrm{c}-\mathrm{h}$ & $29.0 p-q$ & $4 a b$ \\
\hline GEMO-18 & $84.4 \mathrm{c}$ & $5.7 \mathrm{c}-\mathrm{f}$ & $9.7 \mathrm{i}-\mathrm{l}$ & $21.2 \mathrm{f}-\mathrm{l}$ & $31.3 \mathrm{o}-\mathrm{q}$ & $15.4 p-q$ & $104.4 \mathrm{p}-\mathrm{s}$ & $46.2 \mathrm{i}-\mathrm{m}$ & $32.2 \mathrm{~g}-\mathrm{k}$ & 33.5 l-p \\
\hline GEMO-19 & $80.3 \mathrm{c}-\mathrm{f}$ & $4.8 \mathrm{f}-\mathrm{k}$ & $9.6 \mathrm{i}-1$ & $23.3 \mathrm{a}-\mathrm{i}$ & $39.2 \mathrm{~b}-\mathrm{h}$ & $16.5 \mathrm{o}-\mathrm{q}$ & $243.0 \mathrm{ab}$ & $45.2 \mathrm{k}-\mathrm{n}$ & 31.7 h-n & $77.0 \mathrm{a}$ \\
\hline GEMO-20 & $78.0 \mathrm{c}-\mathrm{h}$ & $5.4 \mathrm{~d}-\mathrm{i}$ & $10.7 \mathrm{hi}$ & $23.2 \mathrm{a}-\mathrm{i}$ & $38.2 \mathrm{e}-\mathrm{h}$ & $21.5 \mathrm{e}-\mathrm{j}$ & $177.6 \mathrm{f}-\mathrm{l}$ & $43.8 \mathrm{mn}$ & $34.9 \mathrm{ab}$ & $62.0 \mathrm{~b}-\mathrm{g}$ \\
\hline GEMO-21 & $75.0 \mathrm{~d}-\mathrm{j}$ & $4.7 \mathrm{~g}-\mathrm{k}$ & $10.1 \mathrm{~h}-\mathrm{k}$ & $24.5 \mathrm{a}-\mathrm{c}$ & $37.5 \mathrm{e}-\mathrm{j}$ & $25.7 \mathrm{a}-\mathrm{c}$ & 226.3 a-e & $49.9 \mathrm{~b}-\mathrm{g}$ & 30.9 j-o & 70.0 a-d \\
\hline GEMO-22 & 81.9 c-e & $5.6 \mathrm{c}-\mathrm{g}$ & $7.1 \mathrm{p}-\mathrm{r}$ & 23.9 a-e & $40.0 \mathrm{~b}-\mathrm{f}$ & $21.4 \mathrm{f}-\mathrm{k}$ & $140.31-p$ & $48.5 \mathrm{c}-\mathrm{i}$ & $33.6 \mathrm{~b}-\mathrm{g}$ & 47.0 h-l \\
\hline GEMO-23 & 81.4 c-e & $4.7 \mathrm{~g}-\mathrm{k}$ & 9.6 i-l & $21.8 \mathrm{c}-\mathrm{k}$ & 36.1 g-m & $17.0 \mathrm{~m}-\mathrm{q}$ & $112.5 \mathrm{o}-\mathrm{r}$ & $48.1 \mathrm{~d}-\mathrm{j}$ & $32.4 \mathrm{f}-\mathrm{j}$ & 36.4 l-p \\
\hline GEMO-24 & $79.3 \mathrm{c}-\mathrm{g}$ & $4.6 \mathrm{~h}-\mathrm{k}$ & $6.6 \mathrm{r}$ & $24.9 \mathrm{ab}$ & 39.4 b-f & $24.9 \mathrm{~b}-\mathrm{e}$ & 165.0 h-m & $47.3 \mathrm{~g}-\mathrm{l}$ & $34.5 \mathrm{a}-\mathrm{c}$ & $56.9 c-i$ \\
\hline GEMO-25 & $77.9 \mathrm{c}-\mathrm{h}$ & $5.3 \mathrm{~d}-\mathrm{i}$ & $8.1 \mathrm{n}-\mathrm{p}$ & $20.4 \mathrm{j}-\mathrm{l}$ & $33.8 \mathrm{j}-\mathrm{p}$ & $21.8 \mathrm{~d}-\mathrm{j}$ & $86.6 \mathrm{q}-\mathrm{t}$ & & $34.0 \mathrm{a}-\mathrm{f}$ & $29.5 n-q$ \\
\hline GEMO-26 & & $5.1 \mathrm{e}-\mathrm{j}$ & & $21.9 \mathrm{c}-\mathrm{k}$ & & & & & $33.3 \mathrm{c}-\mathrm{g}$ & \\
\hline GEMO-27 & $69.4 \mathrm{i}-\mathrm{k}$ & $5.5 \mathrm{~d}-\mathrm{h}$ & $8.2 \mathrm{n}-\mathrm{p}$ & $24.5 \mathrm{a}-\mathrm{c}$ & 37.0 e-k & $22.5 c-j$ & $213.0 \mathrm{a}-\mathrm{g}$ & & $32.1 \mathrm{~g}-\mathrm{l}$ & 68.1 a-e \\
\hline GEMO-28 & $74.5 \mathrm{e}-\mathrm{j}$ & $4.3 \mathrm{jk}$ & 8.3 m-o & $24.6 \mathrm{ab}$ & $43.9 \mathrm{a}$ & $24.7 b-f$ & $194.5 \mathrm{~d}-\mathrm{j}$ & $46.0 \mathrm{i}-\mathrm{m}$ & $35.3 \mathrm{a}$ & 68.7 a-e \\
\hline Balcı & $67.7 \mathrm{j}-\mathrm{k}$ & $5.3 \mathrm{~d}-\mathrm{i}$ & $10.4 \mathrm{~h}-\mathrm{k}$ & $24.7 \mathrm{ab}$ & $38.6 \mathrm{c}-\mathrm{h}$ & $21.7 \mathrm{~d}-\mathrm{j}$ & $114.2 \mathrm{n}-\mathrm{r}$ & $45.21-n$ & 34.0 a-e & $38.8 \mathrm{k}-\mathrm{o}$ \\
\hline Centennial & $78.5 \mathrm{c}-\mathrm{h}$ & $6.5 \mathrm{bc}$ & $14.4 \mathrm{a}-\mathrm{c}$ & $22.6 \mathrm{~b}-\mathrm{k}$ & $33.6 \mathrm{k}-\mathrm{q}$ & $14.0 \mathrm{q}-\mathrm{r}$ & $55.7 \mathrm{t}$ & $43.7 \mathrm{mn}$ & $34.1 \mathrm{a}-\mathrm{d}$ & $19.0 \mathrm{q}$ \\
\hline Dinçer 5-18-1 & $79.8 \mathrm{c}-\mathrm{f}$ & $5.5 \mathrm{~d}-\mathrm{h}$ & $11.9 \mathrm{fg}$ & $23.0 \mathrm{~b}-\mathrm{j}$ & $38.8 \mathrm{~b}-\mathrm{i}$ & $23.4 \mathrm{~b}-\mathrm{h}$ & $232.8 \mathrm{a}-\mathrm{d}$ & $49.4 c-h$ & $29.0 p-q$ & 67.4 a-e \\
\hline Gelendost-2 & $100.7 \mathrm{a}$ & $6.0 \mathrm{~b}-\mathrm{e}$ & $12.9 \mathrm{~d}-\mathrm{f}$ & $21.3 \mathrm{e}-\mathrm{k}$ & $37.0 \mathrm{e}-\mathrm{k}$ & $16.8 n-q$ & $92.7 \mathrm{q}-\mathrm{t}$ & $56.2 \mathrm{a}$ & $25.1 \mathrm{r}$ & $23.2 p-q$ \\
\hline Linas & 91.7 b & $4.7 \mathrm{~g}-\mathrm{k}$ & $9.5 \mathrm{j}-\mathrm{l}$ & $23.7 \mathrm{a}-\mathrm{g}$ & $40.4 b-d$ & $14.1 \mathrm{q}$ & $65.2 \mathrm{st}$ & $43.2 \mathrm{n}$ & $35.1 \mathrm{ab}$ & $22.9 p-q$ \\
\hline Montola 2000 & $78.2 \mathrm{c}-\mathrm{h}$ & $6.7 \mathrm{~b}$ & 13.6 c-e & $23.5 a-h$ & 39.6 b-f & 20.1 h-n & $175.7 \mathrm{~g}-\mathrm{l}$ & $50.3 \mathrm{~b}-\mathrm{f}$ & 30.1 o-q & $52.7 \mathrm{f}-\mathrm{j}$ \\
\hline Olas & $72.3 \mathrm{f}-\mathrm{j}$ & $5.5 \mathrm{~d}-\mathrm{h}$ & $10.2 \mathrm{~h}-\mathrm{k}$ & $22.8 \mathrm{~b}-\mathrm{k}$ & $40.0 \mathrm{~b}-\mathrm{f}$ & 20.2 h-n & $89.0 \mathrm{q}-\mathrm{t}$ & $43.3 \mathrm{n}$ & $35.4 \mathrm{a}$ & $31.5 \mathrm{~m}-\mathrm{q}$ \\
\hline Remzibey-05 & $74.3 \mathrm{e}-\mathrm{j}$ & $6.0 \mathrm{~b}-\mathrm{e}$ & $12.6 \mathrm{ef}$ & $23.8 \mathrm{a}-\mathrm{f}$ & $37.4 \mathrm{e}-\mathrm{j}$ & $24.5 \mathrm{~b}-\mathrm{f}$ & $201.3 \mathrm{~b}-\mathrm{h}$ & $50.5 \mathrm{~b}-\mathrm{e}$ & $30.4 \mathrm{n}-\mathrm{p}$ & $61.2 \mathrm{~b}-\mathrm{g}$ \\
\hline W6 9822 & $64.7 \mathrm{k}$ & $7.6 \mathrm{a}$ & $13.5 \mathrm{c}-\mathrm{e}$ & $20.9 \mathrm{~h}-\mathrm{l}$ & $40.3 \mathrm{~b}-\mathrm{e}$ & $17.81-\mathrm{p}$ & $84.6 \mathrm{q}-\mathrm{t}$ & $48.2 \mathrm{~d}-\mathrm{i}$ & 30.6 l-p & $26.00-q$ \\
\hline
\end{tabular}

**: P<0.01, 1: Aynı harflere sahip ortalamalar arasında farklılık bulunmamaktadır.

GEMO popülasyonunda Centennial çeşidi ve 3 hat $(6$, 9 ve 10 nolu) en yüksek tabla sayısına sahip iken, 4 hat $(7,16,22$ ve 24 nolu) en düşük tabla sayısına sahiptir (Tablo 2). GEW6 popülasyonunda Centennial, Montola 2000, Remzibey-05, W6 9822 ve Gelendost-2 genotipleri en yüksek tabla sayısına, 9 hat ise $(4,5,7,9,13,14,16,18$ ve 19 nolu) en düșük tabla sayısına sahiptir (Tablo 3). Diğer taraftan GECE popülasyonunda Centennial (14.4 adet/bitki) çeşidi en yüksek, GECE-2 (6.4 adet/bitki) hattı ise en düşük tabla sayısına sahip olduğu tespit edilmiştir (Tablo 4). Aspirde tabla sayısı için farklı varyasyonlar elde edilse de [12, 14-16], tabla sayısının 5-50 arasında değiştiğini, ancak ekonomik bir verim için 10-12 tablanın olması gerektiği bildirilmektedir [9]. Çalışmamızda, her bir populasyonda yarıya yakın genotipin bu değerler arasında değiştiği tespit edilmiştir. Sonuçlarımız ile diğer çalışmaların sonuçları arasındaki farklılığın genotiplerin ve iklim koşullarının farklı olmasından kaynaklandığı düşünülmektedir. Zira aspirde tabla sayısı orta ve yüksek bir kalıtım derecesine sahip olduğu, aynı genetik yapıya sahip bitkilerin farklı lokasyonlarda yetiştirildiğinde varyasyon oluşabileceği bildirilmektedir [18]. Populasyonlarda tabla çapı bakımından benzer varyasyonlar elde edilmiștir. GEMO popülasyonunda GEMO-1 hattı $(25.8 \mathrm{~mm})$ en yüksek tabla çapına sahip iken, GEMO-9 (18.7 mm) en düşük tabla çapına sahiptir (Tablo 2). GEW6 populasyonunda Balcı çeșidi ile 2 hat $(1,19$ nolu) en yüksek tabla çapına sahip iken, 5 hat $(2,6,10,11,18$ nolu) en düşük tabla çapına sahiptir (Tablo 3). Diğer taraftan GECE populasyonunda 2 hat $(6,20$ nolu) en yüksek tabla çapına, 2 hat $(13,16$ nolu) ise en düşük tabla çapına sahiptir (Tablo 4). Aspirde tabla çapının 10.0-35.0 mm arasında değiștiği bildirilmektedir [9]. Diğer çalışmalarda aspirde tabla çapının 23.3-32.0 mm arasında değiştiği tespit edilmiştir [19]. Aspirde tabla çapı değişen çevre koşullarından kolaylıkla etkilenebilmekte ve değișen çevre koşullarında farklılık gösterebilmektedir [17]. 
Tablo 3. Gelendost- $2 \times$ W6 9822 melezi hatların agronomik ve kalite özellikleri

\begin{tabular}{|c|c|c|c|c|c|c|c|c|c|c|}
\hline & $\begin{array}{l}\text { Bitki } \\
\text { boyu }\end{array}$ & $\begin{array}{c}\text { Dal } \\
\text { sayısı }\end{array}$ & $\begin{array}{l}\text { Tabla } \\
\text { sayısı }\end{array}$ & $\begin{array}{c}\text { Tabla } \\
\text { çapı }\end{array}$ & $\begin{array}{l}1000 \text { tane } \\
\text { ağırlığı }\end{array}$ & $\begin{array}{c}\text { Hasat } \\
\text { indeksi }\end{array}$ & $\begin{array}{l}\text { Tohum } \\
\text { verimi }\end{array}$ & $\begin{array}{c}\text { Kabuk } \\
\text { oranı }\end{array}$ & $\begin{array}{c}\text { Yağ } \\
\text { oranı }\end{array}$ & $\begin{array}{c}\text { Yağ } \\
\text { verimi }\end{array}$ \\
\hline Genotip (F) & $* *$ & $* *$ & $* *$ & $* *$ & $* *$ & $* *$ & $* *$ & $* *$ & $* *$ & $* *$ \\
\hline CV & 4.7 & 14.4 & 12.3 & 6.5 & 3.5 & 10.6 & 12.3 & 3.2 & 4.2 & 12.2 \\
\hline GEW6-1 & $83.2 \mathrm{~cd}^{1}$ & $4.4 \mathrm{e}-\mathrm{h}$ & $7.7 \mathrm{f}-\mathrm{j}$ & $25.0 \mathrm{a}$ & $51.0 \mathrm{a}$ & $25.4 \mathrm{a}$ & $156.3 \mathrm{c}-\mathrm{e}$ & $52.4 \mathrm{~b}$ & $28.0 \mathrm{j}$ & 43.9 ef \\
\hline GEW6-2 & $86.5 \mathrm{bc}$ & $5.0 \mathrm{~d}-\mathrm{h}$ & $8.2 \mathrm{e}-\mathrm{i}$ & $19.7 \mathrm{f}-\mathrm{h}$ & $31.5 \mathrm{kl}$ & $16.1 \mathrm{fg}$ & $80.9 \mathrm{ml}$ & $49.8 \mathrm{~b}-\mathrm{d}$ & $30.9 \mathrm{f}-\mathrm{i}$ & $24.91-p$ \\
\hline GEW6-3 & $77.2 \mathrm{~d}-\mathrm{i}$ & $4.2 \mathrm{f}-\mathrm{h}$ & $8.2 \mathrm{e}-\mathrm{i}$ & $21.8 b-f$ & $35.7 \mathrm{gh}$ & $20.2 \mathrm{~b}-\mathrm{e}$ & $102.8 \mathrm{~h}-\mathrm{l}$ & $48.2 \mathrm{c}-\mathrm{g}$ & $31.0 \mathrm{f}-\mathrm{i}$ & $31.7 \mathrm{~h}-\mathrm{l}$ \\
\hline GEW6-4 & $73.2 \mathrm{f}-\mathrm{k}$ & $4.3 \mathrm{e}-\mathrm{h}$ & $5.5 \mathrm{kl}$ & $21.3 \mathrm{~b}-\mathrm{f}$ & $32.0 \mathrm{j}-\mathrm{l}$ & $12.3 \mathrm{hi}$ & 45.0 no & 48.8 c-e & $32.2 \mathrm{e}-\mathrm{h}$ & $14.5 \mathrm{qr}$ \\
\hline GEW6-5 & $71.3 \mathrm{i}-\mathrm{m}$ & $4.8 \mathrm{~d}-\mathrm{h}$ & $6.1 \mathrm{i}-\mathrm{l}$ & $21.8 \mathrm{~b}-\mathrm{f}$ & $37.7 \mathrm{~d}-\mathrm{g}$ & 19.8 b-f & $83.5 \mathrm{~lm}$ & $46.4 \mathrm{e}-\mathrm{i}$ & $32.4 \mathrm{~d}-\mathrm{h}$ & 27.0 k-p \\
\hline GEW6-6 & $69.3 \mathrm{j}-\mathrm{m}$ & $5.3 \mathrm{c}-\mathrm{g}$ & $7.7 \mathrm{f}-\mathrm{j}$ & $18.2 \mathrm{~h}$ & 37.6 e-g & $17.1 \mathrm{e}-\mathrm{g}$ & $63.9 \mathrm{mn}$ & $46.4 \mathrm{e}-\mathrm{i}$ & $32.4 \mathrm{c}-\mathrm{h}$ & $20.80-q$ \\
\hline GEW6-7 & $70.2 \mathrm{j}-\mathrm{m}$ & $4.8 \mathrm{~d}-\mathrm{h}$ & $7.0 \mathrm{~g}-\mathrm{l}$ & 23.0 a-e & $40.4 \mathrm{bc}$ & $22.1 \mathrm{a}-\mathrm{c}$ & $179.1 \mathrm{bc}$ & $47.6 \mathrm{c}-\mathrm{h}$ & $32.7 \mathrm{~b}-\mathrm{g}$ & $58.4 \mathrm{bc}$ \\
\hline GEW6-8 & $65.5 \mathrm{~lm}$ & $5.5 \mathrm{~b}-\mathrm{f}$ & $7.8 \mathrm{f}-\mathrm{j}$ & 22.8 a-e & $32.4 \mathrm{i}-1$ & $21.9 \mathrm{a}-\mathrm{c}$ & $151.7 \mathrm{de}$ & $48.4 \mathrm{c}-\mathrm{f}$ & $30.8 \mathrm{f}-\mathrm{i}$ & $46.7 \mathrm{de}$ \\
\hline GEW6-9 & 72.7 g-k & $4.2 \mathrm{f}-\mathrm{h}$ & $7.2 \mathrm{~g}-\mathrm{l}$ & 22.6 a-e & $37.6 \mathrm{e}-\mathrm{g}$ & $17.5 \mathrm{e}-\mathrm{g}$ & $106.7 \mathrm{~h}-\mathrm{l}$ & $45.3 \mathrm{~g}-\mathrm{j}$ & 31.9 e-h & $34.0 \mathrm{~g}-\mathrm{k}$ \\
\hline GEW6-10 & 75.9 e-i & $5.2 \mathrm{c}-\mathrm{g}$ & $8.6 \mathrm{~d}-\mathrm{g}$ & $20.7 \mathrm{~d}-\mathrm{h}$ & $40.4 \mathrm{bc}$ & $22.0 \mathrm{a}-\mathrm{c}$ & $125.3 \mathrm{f}-\mathrm{h}$ & $49.9 \mathrm{~b}-\mathrm{d}$ & 30.9 f-i & 38.7 e-i \\
\hline GEW6-11 & $79.8 \mathrm{~d}-\mathrm{f}$ & $5.1 \mathrm{c}-\mathrm{g}$ & $8.4 \mathrm{~d}-\mathrm{h}$ & $18.6 \mathrm{gh}$ & $32.9 \mathrm{i}-\mathrm{k}$ & $10.1 \mathrm{i}$ & 30.2 o & 46.6 e-i & $32.9 \mathrm{a}-\mathrm{g}$ & $10.0 \mathrm{r}$ \\
\hline GEW6-12 & $71.2 \mathrm{i}-\mathrm{m}$ & $5.0 \mathrm{~d}-\mathrm{h}$ & $9.7 \mathrm{~d}-\mathrm{f}$ & $22.4 \mathrm{a}-\mathrm{f}$ & $32.5 \mathrm{i}-\mathrm{l}$ & 19.8 b-f & $120.0 \mathrm{~g}-\mathrm{i}$ & 48.4 & $33.4 \mathrm{a}-\mathrm{f}$ & 40.0 e-g \\
\hline GEW6-13 & $79.5 \mathrm{~d}-\mathrm{g}$ & $4.0 \mathrm{gh}$ & $6.0 \mathrm{j}-\mathrm{l}$ & $23.4 \mathrm{a}-\mathrm{d}$ & $34.8 \mathrm{hi}$ & $22.1 \mathrm{a}-\mathrm{c}$ & $112.2 \mathrm{~h}-\mathrm{k}$ & $47.7 \mathrm{c}-\mathrm{h}$ & 31.9 e-h & $35.7 \mathrm{~g}-\mathrm{j}$ \\
\hline GEW6-14 & 69.4 j-m & $3.9 \mathrm{gh}$ & $6.3 \mathrm{i}-\mathrm{l}$ & 22.8 a-e & 33.9 h-k & $21.6 \mathrm{a}-\mathrm{d}$ & $143.2 \mathrm{e}$ & $47.0 \mathrm{~d}-\mathrm{h}$ & $32.7 \mathrm{~b}-\mathrm{g}$ & $46.7 \mathrm{de}$ \\
\hline GEW6-15 & $81.6 \mathrm{c}-\mathrm{e}$ & 5.7 b-e & $8.6 \mathrm{~d}-\mathrm{g}$ & $21.5 \mathrm{~b}-\mathrm{f}$ & $32.7 \mathrm{i}-\mathrm{k}$ & 19.7 b-f & $145.5 \mathrm{ef}$ & $50.7 \mathrm{bc}$ & $30.8 \mathrm{f}-\mathrm{i}$ & $44.8 \mathrm{ef}$ \\
\hline GEW6-16 & $65.8 \mathrm{~lm}$ & $4.0 \mathrm{gh}$ & $6.4 \mathrm{~h}-\mathrm{l}$ & $24.1 \mathrm{ab}$ & $32.0 \mathrm{j}-\mathrm{l}$ & $19.0 \mathrm{c}-\mathrm{f}$ & 87.8 k-m & $45.3 \mathrm{~g}-\mathrm{j}$ & $34.8 \mathrm{a}-\mathrm{d}$ & $30.5 \mathrm{i}-\mathrm{n}$ \\
\hline GEW6-17 & $78.0 \mathrm{~d}-\mathrm{i}$ & $5.0 \mathrm{~d}-\mathrm{h}$ & $7.7 \mathrm{f}-\mathrm{j}$ & 21.4 b-f & $34.0 \mathrm{~h}-\mathrm{j}$ & 20.1 b-e & $81.8 \mathrm{~lm}$ & $45.7 \mathrm{f}-\mathrm{j}$ & $32.6 \mathrm{~b}-\mathrm{g}$ & 26.8 k-p \\
\hline GEW6-18 & $65.4 \mathrm{~lm}$ & $4.0 \mathrm{gh}$ & $6.7 \mathrm{~g}-\mathrm{l}$ & $20.2 \mathrm{e}-\mathrm{h}$ & $30.2 \mathrm{l}$ & $16.6 \mathrm{e}-\mathrm{g}$ & 95.6 i-l & $49.1 \mathrm{c}-\mathrm{e}$ & $29.9 \mathrm{~h}-\mathrm{j}$ & 28.5 j-o \\
\hline GEW6-19 & 78.9 d-h & $3.6 \mathrm{~h}$ & 5.21 & $24.7 \mathrm{a}$ & $42.1 \mathrm{~b}$ & 21.9 a-c & $115.9 \mathrm{~h}-\mathrm{j}$ & $47.9 \mathrm{c}-\mathrm{h}$ & 32.0 e-h & $37.2 \mathrm{f}-\mathrm{i}$ \\
\hline GEW6-20 & $78.5 \mathrm{~d}-\mathrm{h}$ & $4.4 \mathrm{e}-\mathrm{h}$ & $7.3 \mathrm{~g}-\mathrm{k}$ & $24.0 \mathrm{ab}$ & $39.1 \mathrm{c}-\mathrm{f}$ & $24.7 \mathrm{a}$ & $180.1 \mathrm{bc}$ & $45.1 \mathrm{~h}-\mathrm{j}$ & $34.9 \mathrm{a}-\mathrm{c}$ & $62.7 \mathrm{ab}$ \\
\hline Balcı & $67.7 \mathrm{k}-\mathrm{m}$ & $5.3 \mathrm{c}-\mathrm{g}$ & $10.4 \mathrm{~cd}$ & $24.7 \mathrm{a}$ & $38.6 \mathrm{c}-\mathrm{f}$ & $21.7 \mathrm{a}-\mathrm{d}$ & $114.2 \mathrm{~h}-\mathrm{k}$ & $45.2 \mathrm{~g}-\mathrm{j}$ & 34.0 a-e & 38.8 e-h \\
\hline Centennial & $78.5 \mathrm{~d}-\mathrm{h}$ & $6.5 \mathrm{a}-\mathrm{c}$ & $14.4 \mathrm{a}$ & 22.6 a-e & $33.6 \mathrm{~h}-\mathrm{k}$ & $14.0 \mathrm{gh}$ & $55.7 \mathrm{n}$ & $43.7 \mathrm{ij}$ & $34.1 \mathrm{a}-\mathrm{e}$ & $19.0 \mathrm{pq}$ \\
\hline Dinçer 5-18-1 & $79.8 \mathrm{~d}-\mathrm{f}$ & $5.5 \mathrm{~b}-\mathrm{f}$ & $11.9 \mathrm{bc}$ & 23.0 a-e & $38.8 \mathrm{c}-\mathrm{f}$ & $23.4 \mathrm{ab}$ & $232.8 \mathrm{a}$ & $49.4 c-e$ & $29.0 \mathrm{ij}$ & $67.4 \mathrm{a}$ \\
\hline Gelendost-2 & $100.7 \mathrm{a}$ & $6.0 \mathrm{~b}-\mathrm{d}$ & $12.9 \mathrm{ab}$ & $21.3 \mathrm{~b}-\mathrm{f}$ & $37.0 \mathrm{fg}$ & $16.8 \mathrm{e}-\mathrm{g}$ & $92.7 \mathrm{j}-\mathrm{l}$ & $56.2 \mathrm{a}$ & $25.1 \mathrm{k}$ & $23.2 n-p$ \\
\hline Linas & $91.7 \mathrm{~b}$ & $4.7 \mathrm{~d}-\mathrm{h}$ & $9.5 \mathrm{~d}-\mathrm{f}$ & 23.7 a-c & $40.4 \mathrm{bc}$ & $14.1 \mathrm{gh}$ & $65.2 \mathrm{mn}$ & $43.2 \mathrm{j}$ & $35.1 \mathrm{ab}$ & 22.9 n-p \\
\hline Montola 2000 & $78.2 \mathrm{~d}-\mathrm{h}$ & $6.7 \mathrm{ab}$ & $13.6 \mathrm{ab}$ & $23.5 \mathrm{a}-\mathrm{d}$ & 39.6 c-e & 20.1 b-e & $175.7 \mathrm{~cd}$ & $50.3 \mathrm{bc}$ & $30.1 \mathrm{~h}-\mathrm{j}$ & $52.7 \mathrm{~cd}$ \\
\hline Olas & $72.3 \mathrm{~h}-1$ & $5.5 \mathrm{~b}-\mathrm{f}$ & $10.2 \mathrm{c}-\mathrm{e}$ & 22.8 a-e & $40.0 \mathrm{~b}-\mathrm{d}$ & $20.2 \mathrm{~b}-\mathrm{e}$ & 89.0 k-m & $43.3 \mathrm{j}$ & $35.4 \mathrm{a}$ & $31.5 \mathrm{~h}-\mathrm{m}$ \\
\hline Remzibey-05 & $74.3 \mathrm{f}-\mathrm{k}$ & $6.0 \mathrm{~b}-\mathrm{d}$ & $12.6 \mathrm{ab}$ & $23.8 \mathrm{ab}$ & $37.4 \mathrm{e}-\mathrm{g}$ & $24.5 \mathrm{a}$ & $201.3 \mathrm{~b}$ & $50.5 \mathrm{bc}$ & $30.4 \mathrm{~g}-\mathrm{j}$ & $61.2 \mathrm{ab}$ \\
\hline W6 9822 & $64.7 \mathrm{~m}$ & $7.6 \mathrm{a}$ & $13.5 \mathrm{ab}$ & $20.9 c-g$ & $40.3 \mathrm{bc}$ & $17.8 \mathrm{~d}-\mathrm{g}$ & $84.6 \mathrm{~lm}$ & $48.2 \mathrm{c}-\mathrm{g}$ & $30.6 \mathrm{~g}-\mathrm{i}$ & $26.0 \mathrm{k}-\mathrm{p}$ \\
\hline
\end{tabular}

**: P<0.01, 1: Aynı harflere sahip ortalamalar arasında farklılık bulunmamaktadır.

Tablo 4. Gelendost- $2 \times$ Centennial melezi hatların agronomik ve kalite özellikleri

\begin{tabular}{|c|c|c|c|c|c|c|c|c|c|c|}
\hline & $\begin{array}{l}\text { Bitki } \\
\text { boyu }\end{array}$ & $\begin{array}{c}\text { Dal } \\
\text { sayıs! }\end{array}$ & $\begin{array}{l}\text { Tabla } \\
\text { sayısı }\end{array}$ & $\begin{array}{c}\text { Tabla } \\
\text { çapı }\end{array}$ & $\begin{array}{l}1000 \text { tane } \\
\text { ağırlığı }\end{array}$ & $\begin{array}{c}\text { Hasat } \\
\text { indeksi }\end{array}$ & $\begin{array}{l}\text { Tohum } \\
\text { verimi }\end{array}$ & $\begin{array}{c}\text { Kabuk } \\
\text { oranı }\end{array}$ & $\begin{array}{c}\text { Yağ } \\
\text { oranı }\end{array}$ & $\begin{array}{c}\text { Yağ } \\
\text { verimi }\end{array}$ \\
\hline Genotip (F) & $* *$ & $* *$ & $* *$ & $* *$ & $*$ & $* *$ & $* *$ & $* *$ & $* *$ & $* *$ \\
\hline CV & 6.9 & 14.4 & 11.2 & 7.4 & 6.6 & 13.1 & 12.7 & 3.6 & 4.3 & 12.9 \\
\hline GECE-1 & $76.8 c-e^{1}$ & $5.3 \mathrm{a}-\mathrm{g}$ & $7.4 \mathrm{f}-\mathrm{h}$ & $22.4 \mathrm{a}-\mathrm{d}$ & 37.9 a-e & $16.5 \mathrm{~g}-\mathrm{j}$ & $101.9 \mathrm{e}-\mathrm{i}$ & $48.3 \mathrm{~b}-\mathrm{f}$ & $31.9 \mathrm{c}-\mathrm{f}$ & $32.7 \mathrm{~d}-\mathrm{g}$ \\
\hline GECE-2 & $76.1 \mathrm{c}-\mathrm{e}$ & $4.0 \mathrm{~g}$ & $6.4 \mathrm{~h}$ & $23.1 \mathrm{a}-\mathrm{d}$ & 37.6 a-e & $19.3 \mathrm{~b}-\mathrm{h}$ & $101.1 \mathrm{f}-\mathrm{i}$ & $46.1 \mathrm{~d}-\mathrm{k}$ & $32.4 \mathrm{~b}-\mathrm{f}$ & $32.9 \mathrm{~d}-\mathrm{g}$ \\
\hline GECE-3 & $76.0 \mathrm{c}-\mathrm{e}$ & $5.0 \mathrm{c}-\mathrm{g}$ & $8.6 \mathrm{~b}-\mathrm{h}$ & $23.0 \mathrm{a}-\mathrm{d}$ & 36.6 a-e & 21.5 a-e & $98.0 \mathrm{f}-\mathrm{i}$ & $48.6 \mathrm{~b}-\mathrm{e}$ & $33.1 \mathrm{a}-\mathrm{d}$ & $32.5 \mathrm{~d}-\mathrm{h}$ \\
\hline GECE-4 & 76.7 c-e & $5.0 \mathrm{~b}-\mathrm{g}$ & $8.4 \mathrm{~b}-\mathrm{h}$ & $23.2 \mathrm{a}-\mathrm{d}$ & 36.6 a-e & $18.8 \mathrm{c}-\mathrm{h}$ & $118.4 \mathrm{~d}-\mathrm{f}$ & $46.1 \mathrm{~d}-\mathrm{k}$ & 32.9 a-e & $38.8 \mathrm{~cd}$ \\
\hline GECE-5 & $77.2 \mathrm{c}-\mathrm{e}$ & $4.8 \mathrm{c}-\mathrm{g}$ & $9.9 \mathrm{a}-\mathrm{h}$ & $23.3 \mathrm{a}-\mathrm{d}$ & 36.4 a-e & $18.4 \mathrm{c}-\mathrm{i}$ & $127.1 \mathrm{de}$ & $47.9 \mathrm{~b}-\mathrm{h}$ & $31.4 \mathrm{c}-\mathrm{g}$ & $39.8 \mathrm{~cd}$ \\
\hline GECE-6 & $75.7 \mathrm{c}-\mathrm{e}$ & $4.8 \mathrm{c}-\mathrm{g}$ & $8.4 \mathrm{~b}-\mathrm{h}$ & $25.7 \mathrm{a}$ & 35.6 a-e & $22.2 \mathrm{a}-\mathrm{c}$ & $111.0 \mathrm{~d}-\mathrm{h}$ & $45.5 \mathrm{e}-\mathrm{k}$ & $33.2 \mathrm{a}-\mathrm{d}$ & $37.0 \mathrm{c}-\mathrm{f}$ \\
\hline GECE-7 & $79.0 \mathrm{~cd}$ & $7.8 \mathrm{a}$ & 13.2 a-e & $24.5 \mathrm{ab}$ & 38.1 a-e & $17.4 \mathrm{~d}-\mathrm{i}$ & $114.7 \mathrm{~d}-\mathrm{g}$ & $46.7 \mathrm{~d}-\mathrm{i}$ & 32.7 a-e & $37.5 \mathrm{c}-\mathrm{e}$ \\
\hline GECE-8 & $75.1 \mathrm{c}-\mathrm{e}$ & $7.2 \mathrm{a}-\mathrm{c}$ & 11.7 a-h & $23.1 \mathrm{a}-\mathrm{d}$ & 34.6 c-e & $17.4 \mathrm{~d}-\mathrm{i}$ & $130.5 \mathrm{~d}$ & $46.1 \mathrm{~d}-\mathrm{k}$ & 33.9 a-c & $44.1 \mathrm{c}$ \\
\hline GECE-9 & $77.8 \mathrm{c}-\mathrm{e}$ & $7.7 \mathrm{ab}$ & $14.0 \mathrm{ab}$ & $23.4 \mathrm{a}-\mathrm{d}$ & $34.5 \mathrm{c}-\mathrm{e}$ & $16.6 \mathrm{~g}-\mathrm{j}$ & $93.6 \mathrm{f}-\mathrm{i}$ & $44.9 \mathrm{~g}-\mathrm{k}$ & $34.9 \mathrm{ab}$ & $32.7 \mathrm{~d}-\mathrm{g}$ \\
\hline GECE-10 & $77.4 \mathrm{c}-\mathrm{e}$ & $5.6 \mathrm{a}-\mathrm{g}$ & $10.1 \mathrm{a}-\mathrm{h}$ & $22.5 \mathrm{a}-\mathrm{d}$ & 35.3 a-e & $15.8 \mathrm{~g}-\mathrm{j}$ & $89.1 \mathrm{~g}-\mathrm{j}$ & $47.1 \mathrm{c}-\mathrm{h}$ & 32.8 a-e & $29.2 \mathrm{e}-\mathrm{j}$ \\
\hline GECE-11 & $78.6 \mathrm{~cd}$ & $4.9 \mathrm{c}-\mathrm{g}$ & $12.1 \mathrm{a}-\mathrm{g}$ & 23.9 a-c & 37.0 a-e & $17.0 e-j$ & $91.7 \mathrm{~g}-\mathrm{i}$ & $47.1 \mathrm{c}-\mathrm{h}$ & $32.0 \mathrm{c}-\mathrm{f}$ & $29.4 \mathrm{e}-\mathrm{j}$ \\
\hline GECE-12 & $2.9 \mathrm{bc}$ & $4.7 \mathrm{~d}-\mathrm{g}$ & $8.2 \mathrm{c}-\mathrm{h}$ & $22.5 \mathrm{a}-\mathrm{d}$ & 36.2 a-e & $15.4 \mathrm{~h}-\mathrm{k}$ & $89.7 \mathrm{~g}-\mathrm{j}$ & $44.5 \mathrm{~h}-\mathrm{k}$ & $33.2 \mathrm{a}-\mathrm{d}$ & $29.7 e-j$ \\
\hline GECE-13 & $80.5 \mathrm{~cd}$ & $5.1 \mathrm{~b}-\mathrm{g}$ & $7.9 \mathrm{~d}-\mathrm{h}$ & $20.3 \mathrm{~d}$ & 33.0 e & $11.3 \mathrm{k}$ & $54.8 \mathrm{k}$ & $47.1 \mathrm{c}-\mathrm{h}$ & $31.1 \mathrm{~d}-\mathrm{g}$ & $17.1 \mathrm{l}$ \\
\hline GECE-14 & $82.8 \mathrm{bc}$ & $4.4 \mathrm{e}-\mathrm{g}$ & $7.1 \mathrm{~g}-\mathrm{h}$ & $22.3 \mathrm{a}-\mathrm{d}$ & 36.2 a-e & $12.4 \mathrm{j}-\mathrm{k}$ & $94.5 \mathrm{f}-\mathrm{i}$ & $46.2 \mathrm{~d}-\mathrm{k}$ & $30.3 \mathrm{e}-\mathrm{g}$ & $28.5 \mathrm{f}-\mathrm{j}$ \\
\hline GECE-15 & 78.0 c-e & $4.3 \mathrm{f}-\mathrm{g}$ & $8.7 \mathrm{~b}-\mathrm{h}$ & $24.3 \mathrm{ab}$ & 37.2 a-e & $19.1 \mathrm{~b}-\mathrm{h}$ & $81.6 \mathrm{ij}$ & $46.9 \mathrm{~d}-\mathrm{i}$ & $31.8 c-f$ & $26.0 \mathrm{~g}-\mathrm{k}$ \\
\hline GECE-16 & $72.8 \mathrm{c}-\mathrm{f}$ & $5.1 \mathrm{~b}-\mathrm{g}$ & $10.4 \mathrm{a}-\mathrm{h}$ & $20.4 \mathrm{~d}$ & $35.5 \mathrm{a}-\mathrm{e}$ & $16.2 \mathrm{~g}-\mathrm{j}$ & $77.7 \mathrm{i}-\mathrm{k}$ & $49.0 \mathrm{~b}-\mathrm{d}$ & $31.0 \mathrm{~d}-\mathrm{g}$ & $24.0 \mathrm{i}-\mathrm{l}$ \\
\hline GECE-17 & $76.8 c-e$ & $4.7 \mathrm{~d}-\mathrm{g}$ & $9.6 \mathrm{a}-\mathrm{h}$ & $22.6 \mathrm{a}-\mathrm{d}$ & 34.4 c-e & 14.9 h-k & $80.7 \mathrm{ij}$ & $47.1 \mathrm{c}-\mathrm{h}$ & $32.4 \mathrm{~b}-\mathrm{f}$ & $26.2 \mathrm{~g}-\mathrm{k}$ \\
\hline GECE-18 & $70.0 \mathrm{~d}-\mathrm{f}$ & $4.8 \mathrm{~d}-\mathrm{g}$ & $7.8 \mathrm{~d}-\mathrm{h}$ & $23.5 \mathrm{a}-\mathrm{d}$ & $35.1 \mathrm{~b}-\mathrm{e}$ & 21.3 a-f & $103.6 \mathrm{e}-\mathrm{i}$ & $46.2 \mathrm{~d}-\mathrm{k}$ & $32.5 \mathrm{~b}-\mathrm{f}$ & $33.6 \mathrm{~d}-\mathrm{g}$ \\
\hline GECE-19 & $74.5 \mathrm{c}-\mathrm{f}$ & $7.1 \mathrm{a}-\mathrm{d}$ & $8.9 \mathrm{~b}-\mathrm{h}$ & $23.1 \mathrm{a}-\mathrm{d}$ & $38.2 \mathrm{a}-\mathrm{d}$ & 16.9 e-j & 91.9 g-i & $46.5 \mathrm{~d}-\mathrm{j}$ & $31.1 \mathrm{~d}-\mathrm{g}$ & $28.5 \mathrm{f}-\mathrm{j}$ \\
\hline GECE-20 & $79.8 \mathrm{~cd}$ & $4.7 \mathrm{~d}-\mathrm{g}$ & $7.5 \mathrm{e}-\mathrm{h}$ & $24.8 \mathrm{a}$ & $38.9 \mathrm{a}-\mathrm{c}$ & $21.4 \mathrm{a}-\mathrm{f}$ & $98.8 \mathrm{f}-\mathrm{i}$ & $47.4 \mathrm{~b}-\mathrm{h}$ & $31.7 \mathrm{c}-\mathrm{f}$ & $31.4 \mathrm{~d}-\mathrm{j}$ \\
\hline Balcı & 67.7 ef & $5.3 \mathrm{a}-\mathrm{g}$ & 10.4 a-h & $24.7 \mathrm{ab}$ & $38.6 \mathrm{a}-\mathrm{d}$ & $21.7 \mathrm{a}-\mathrm{d}$ & $114.2 \mathrm{~d}-\mathrm{g}$ & $45.2 \mathrm{f}-\mathrm{k}$ & $34.0 \mathrm{a}-\mathrm{c}$ & $38.8 \mathrm{~cd}$ \\
\hline Centennial & $78.5 \mathrm{~cd}$ & $6.5 \mathrm{a}-\mathrm{f}$ & $14.4 \mathrm{a}$ & $22.6 \mathrm{a}-\mathrm{d}$ & 33.6 d-e & $14.0 \mathrm{i}-\mathrm{k}$ & $55.7 \mathrm{k}$ & $43.7 \mathrm{i}-\mathrm{k}$ & $34.1 \mathrm{a}-\mathrm{c}$ & $19.0 \mathrm{kl}$ \\
\hline Dinçer 5-18-1 & $79.8 \mathrm{~cd}$ & $5.5 \mathrm{a}-\mathrm{g}$ & 11.9 a-h & $23.0 \mathrm{a}-\mathrm{d}$ & $38.8 \mathrm{a}-\mathrm{d}$ & $23.4 \mathrm{ab}$ & $232.8 \mathrm{a}$ & $49.4 \mathrm{~b}-\mathrm{d}$ & $29.0 \mathrm{~g}$ & $67.4 \mathrm{a}$ \\
\hline Gelendost-2 & $100.7 \mathrm{a}$ & $6.0 \mathrm{a}-\mathrm{g}$ & $12.9 \mathrm{a}-\mathrm{f}$ & $21.3 \mathrm{~b}-\mathrm{d}$ & 37.0 a-e & $16.8 \mathrm{f}-\mathrm{j}$ & $92.7 \mathrm{f}-\mathrm{i}$ & $56.2 \mathrm{a}$ & $25.1 \mathrm{~h}$ & $23.2 \mathrm{i}-1$ \\
\hline Linas & $91.7 \mathrm{~b}$ & $4.7 \mathrm{~d}-\mathrm{g}$ & $9.5 \mathrm{a}-\mathrm{h}$ & $23.7 \mathrm{a}-\mathrm{d}$ & $40.4 \mathrm{a}$ & $14.1 \mathrm{i}-\mathrm{k}$ & $65.2 \mathrm{jk}$ & $43.2 \mathrm{k}$ & $35.1 \mathrm{ab}$ & $22.9 \mathrm{j}-\mathrm{l}$ \\
\hline Montola 2000 & 78.2 c-e & $6.7 \mathrm{a}-\mathrm{e}$ & $13.6 \mathrm{a}-\mathrm{c}$ & $23.5 \mathrm{a}-\mathrm{d}$ & $39.6 a-c$ & $20.1 \mathrm{a}-\mathrm{g}$ & $175.7 \mathrm{c}$ & $50.3 \mathrm{bc}$ & $30.1 \mathrm{f}-\mathrm{g}$ & $52.7 \mathrm{~b}$ \\
\hline Olas & $72.3 \mathrm{c}-\mathrm{f}$ & $5.5 \mathrm{a}-\mathrm{g}$ & $10.2 \mathrm{a}-\mathrm{h}$ & $22.8 \mathrm{a}-\mathrm{d}$ & $40.0 \mathrm{ab}$ & $20.2 \mathrm{a}-\mathrm{g}$ & $89.0 \mathrm{~g}-\mathrm{j}$ & $43.3 \mathrm{jk}$ & $35.4 \mathrm{a}$ & $31.5 \mathrm{~d}-\mathrm{i}$ \\
\hline Remzibey-05 & $74.3 \mathrm{c}-\mathrm{f}$ & $6.0 \mathrm{a}-\mathrm{g}$ & $12.6 \mathrm{a}-\mathrm{g}$ & $23.8 \mathrm{a}-\mathrm{c}$ & 37.4 a-e & $24.5 \mathrm{a}$ & $201.3 \mathrm{~b}$ & $50.5 \mathrm{~b}$ & $30.4 \mathrm{e}-\mathrm{g}$ & $61.2 \mathrm{a}$ \\
\hline W6 9822 & $64.7 \mathrm{f}$ & $7.6 \mathrm{a}-\mathrm{c}$ & $13.5 \mathrm{a}-\mathrm{d}$ & $20.9 \mathrm{c}-\mathrm{d}$ & $40.3 \mathrm{a}$ & $17.8 c-i$ & $84.6 \mathrm{~h}-\mathrm{j}$ & $48.2 \mathrm{~b}-\mathrm{g}$ & $30.6 \mathrm{~d}-\mathrm{g}$ & $26.0 \mathrm{~g}-\mathrm{k}$ \\
\hline
\end{tabular}

${ }^{*}: \mathrm{P}<0.05,{ }^{* *}: \mathrm{P}<0.01,1$ : Aynı harflere sahip ortalamalar arasında farklılık bulunmamaktadır. 
Aspirde 1000 tane ağırlı̆̆ı yüksek kalıtım derecesi gösteren bir özellik olması nedeniyle, 1000 tane ağırlı̆̆ına göre yapılacak seleksiyonlarda yüksek tohum verimine sahip tiplerin seçilmesine dolaylı olarak katkı sağlayacaktır [10]. İdeal verim için aspirde 1000 tane ağırlığının 50 g'ın üzerinde olması gerektiği rapor edilmektedir [9]. Çalışmamızda 1000 tane ağırlığı GEMO popülasyonunda 3 hat $(4,12,28$ nolu) en yüksek 1000 tane ağırlığına sahip iken, Centennial çeşidi ile 6 hat $(7,8,14,17,18,26$ nolu) en düșük ağırlığına sahip olduğu tespit edilmiștir (Tablo 2). GEW6 populasyonunda ise GEW6-1 (51.0 g) en yüksek 1000 tane ağırlığına sahip iken, 6 hat $(2,4,8$, 12, 16, 18 nolu) en düşük 1000 tane ağırlığına sahiptir (Tablo 3). GECE populasyonunda ise Linas ve W6 9822 genotipleri en yüksek 1000 tane ağırlı̆̆ına sahip iken 15 hat ve Centennial hariç diğer standart genotipler aynı istatistiksel grupta yer almışlardır (Tablo 4). GECE-13 (33.0 g) ise en düşük 1000 tane ağırlığına sahiptir. Çalışmamızda 50 g'ın üzerinde GEW6-1 hattı bu sınırın üzerinde bir değer (51.0 g) vermiştir. Ülkemizde ve dünyada yapılan çalışmalarda aspir genotiplerinde 1000 tane ağırlığ 17.8-54.0 g arasında geniş bir varyasyon gösterdiği belirlenmiştir [14-17].

Hasat indeksi diğer bitkilerde olduğu gibi aspirde de önemli ıslah amaçlarından birisidir. Çalışmamızda GEMO popülasyonunda 3 hat $(13,16$ ve 21 nolu) en yüksek hasat indeksine sahip iken, Centennial çeşidi ile GEMO-26 hattı en düşük hasat indeksine sahiptir (Tablo 2). GEW6 populasyonunda Remzibey-05 çeşidi ile 2 hat (1 ve 20 nolu) en yüksek hasat indeksine sahip iken, bunları Dinçer 5-18-1, GEW6-7, $13,10,8,19,14$ ve Balcl genotipleri takip etmiștir (Tablo 3). GECE populasyonunda ise Remzibey-05 (\% 24.5), Dinçer 5-18-1 (\% 23.4), GECE-6, (\% 22.2), Balcı (\% 21.7) GECE-3 (\% 21.5), 20 (\%21.4), 18 (\% 21.3), Olas (\% 20.2) ve Montola 2000 (\% 20.1) çeșidi en yüksek hasat indeksine, GECE-13 (\% 11.3) ise en düşük hasat indeksine sahiptir (Tablo 4). Aspirde hasat indeksinin kalıtımında eklemeli etkili allellerin daha etkin rol aldığı ve hasat değerinin yükseltilmesinde çevre faktörlerinin etkisinin önemli düzeyde olduğu rapor edilmektedir [15]. Aspirde hasat indeksi ile ilgili araştırıcılar tarafından farklı sonuçlar alınmıştır. Lakshmi Prayaga vd. [20] aspirde hasat indeksinin \%5.0-36.0 ve Parameshwar [21] \% 22.5-37.5 arasında değiștiğini rapor etmişlerdir. Çalıșmamızda elde edilen sonuçlar ile uyumlu bulunmuştur.

GEMO melez hatlarında tohum verimi 55.7-252.6 $\mathrm{kg} / \mathrm{da}$, GEW6 melez hatlarında $30.2-232.8 \mathrm{~kg} / \mathrm{da}$ ve GECE melez hatlarında 54.8-232.8 kg/da arasında değişim göstermiştir. GEMO popülasyonunda Dinçer 5-18-1 çeşidi ve 7 hat $(6,10,14,17,19,21$ ve 27 nolu) en yüksek tohum verimine sahip iken, Centennial $(55.7 \mathrm{~kg} / \mathrm{da})$ çeşidi en düșük tohum verimine; GEW6 populasyonunda Dinçer 5-18-1 $(232.8 \mathrm{~kg} / \mathrm{da})$ çeşidi en yüksek tohum verimine sahip iken, GEW6-11 (30.2 kg/da) en düşük tohum verimine; GECE populasyonunda Dinçer 5-18-1 (232.8 kg/da) çeşidi en yüksek tohum verimine, Centennial (55.7 kg/da) çeșidi ve GECE-13 (54.8 $\mathrm{kg} / \mathrm{da}$ ) hattı ise en düşük tohum verimine sahip olduğu tespit edilmiştir (Tablo 2, 3, 4). Aspirde tohum veriminin kalıtımında eklemeli etkiye sahip birçok gen etkili olduğu için düşük bir kalıtım derecesi göstermektedir $[9,15]$. Bu nedenle iklim, toprak ve genetik faktörlere bağlı farklı tohum verimleri elde edilebilir. Dünyada kurak koşullarda aspirden 40-170 $\mathrm{kg} / \mathrm{da}$ tohum verimi elde edilirken, uygun toprak ve iklim koșullarında verim $300 \mathrm{~kg} / \mathrm{da}^{\prime} \mathrm{a}$ kadar yükselebilmektedir [9]. Çalışmamızda elde edilen verim değerleri 170 kg'ın üzerinde olan GEMO populasyonunda 16 hat, GEW6 populasyonunda 2 hat bulunmasına rağmen, GECE populasyonunda bu değerin üzerine hat bulunmamaktadır. Yapılan diğer çalışmalarda aspirde tohum veriminin 6.9-343.4 $\mathrm{kg} / \mathrm{da}$ arasında değiştiği rapor edilmektedir [14-17, 22].

GEMO popülasyonunda kabuk oranı \% 43.2-57.9, GEW6'da \% 43.2-56.2 ve GECE'de \% 43.2-56.2 arasında değişim göstermiştir. GEMO popülasyonunda Gelendost-2 ve GEMO-12 hatları en yüksek kabuk oranına sahip iken, Olas ve Linas çeşitleri en düşük kabuk oranına sahiptir. GEW6 populasyonunda Dinçer 5-18-1 (232.8 kg/da) çeşidi en yüksek kabuk oranına sahip iken, GEW6-11 (30.2 $\mathrm{kg} / \mathrm{da}$ ) en düşük kabuk oranına sahiptir. GECE populasyonunda Olas ve Linas çeşitleri en yüksek kabuk oranına, Linas çeşidi ise en düşük kabuk oranına sahiptir. GEMO populasyonunda 5 hat $(1,19$, 20,25 ve 26 nolu), GEW6 populasyonunda 4 hat (9, 16,17 ve 20 nolu) ve GECE populasyonunda ise 8 hat $(2,4,6,8,9,12,14$ ve 18 nolu) istatiksel olarak en düşük kabuk oranına sahip grupta yer almışlardır (Tablo 2, 3, 4). Aspirde kabuk kalınlığını kontrol eden genler pleotropik etki göstererek, aynı zamanda sap hücrelerinde sekonder duvar kalınlığını ve çiçekte anter kapalılığını (yapısal kısırlık) kontrol ettiği için, ince tohum kabuklu bitkiler daha zayıf saplı ve düşük fertiliteye sahiptirler [9]. Bu yüzden aspir ıslahçıları tohum verimi ve yağ oranını etkilemeyecek düzeyde minimum kabuk oranına sahip aspir genotiplerini geliştirmeye çalışmaktadır. Yapılan çalışmalarda Weiss [9] \% 35-50 ve Reddy vd. [16] \% 39.5-50.8 arasında değiştiğini rapor etmiştir. Çalışmamızda popülasyonlarda elde edilen kabuk oranı varyasyonu yukarıda belirtilen araştırmaların varyasyonu ile benzerlik göstermiş ancak düşük kabuk oranına sahip genotip elde edilememiştir.

Populasyonların yağ oranı incelendiğinde bütün popülasyonlarda Olas çeşidi en yüksek (\% 35.4), Gelendost-2 hattı en düşük (\% 25.1) yağ oranına sahip olduğu tespit edilmiştir. Ancak GEMO popülasyonunda GEMO-1, 20, 24, 25, 28 hatları, GEW6'da GEW6-11, 12, 16, 20 hatları, GECE popülasyonunda GECE-3, 4, 6, 7, 8, 9 ve 10 nolu hatlar 
Olas çeşidi ile aynı istatistiki grupta yer almıştır (Tablo 2, 3, 4). Aspirde yağ oranının az sayıda eklemeli etkiye sahip alleller tarafından kontrol edildiği, dolayısıyla orta ve yüksek oranda kalıtım derecesine sahip olduğu araştırıcılar tarafından vurgulanmıștır [11]. Bu nedenle, aspir hatlarında belirlenen yă̆ oranının olası bir yabancı döllenme olmadığı takdirde sonraki generasyonlara aktarılabilir ve seleksiyonda başarı şansı artabilir. Çalışmamızda Olas çeşidinden yüksek yağ oranına sahip hatlar olmamasına rağmen, istatistiksel olarak aynı grupta yer alan hatlar ümitvar görülmektedir. Yapılan birçok araştırmada aspirde yağ oranı bakımından benzer varyasyonlar yakalansa da farklı sonuçlar elde edilmiştir. Fernandez-Martinez vd. [23] 37 ülkeden topladıkları 200 aspir genotipinde yağ oranının \% 20.1-40.0, Johnson vd. [24] 137 introdüksiyon materyalinde yağ oranının \% 13.046.0, Reddy vd. [16] \% 27.8-31.6 ve Erbaş vd. [24] 39 aspir çeşidinde \% 22.6-33.8 arasında değiştiğini rapor etmişlerdir.

Yağ verimi GEMO popülasyonunda 19.0-77.2 kg/da arasında değişirken, en yüksek yağ verimi GEMO-2, 6, $10,14,16,17,19,21,27,28$ nolu hatlar ve Dinçer 518-1 çeşidinde, en düşük ise Centennial çeșidinde tespit edilmiştir (Tablo 2). GEW6 popülasyonunda 10.0-67.4 kg/da arasında değişim gösterirken, Dinçer-5-18-1 ve Remzibey-05 çeşitleri ile GEW6-20 hattı en yüksek, GEW6-11 hattı ise en düşük yağ verimine sahip genotip olarak belirlenmiștir (Tablo 3). GECE popülasyonunda ise yağ verimi 17.1-67.4 $\mathrm{kg} / \mathrm{da}$ arasında değişmiş ve en yüksek yağ verimi Dinçer-5-18-1 ve Remzibey-05 çeşitlerinde, en düşük ise GECE-13 hattında saptanmıştır (Tablo 4). Aspirde yağ verimi değişen çevre koşullarından kolaylıkla etkilenebildiği rapor edilmektedir [15]. Yapılan çalışmalarda aspirde yağ verimi için geniş bir varyasyon elde edilmiş $[16,25]$, sonuçlarımız bu sınırlar arasında yer almıştır. Çalışmadan elde ettiğimiz sonuçlara bakıldığında bütün özellikler bakımından diğer araştırıcıların çalışmaları ile farklılıklar gösterebileceği, bu farklılığın kullanılan genotiplerin ve iklim koşullarının farklı olmasından kaynaklandığı düşünülmektedir.

Aspir hat ve çeşitlerinin yağ asitleri kompozisyonu sonuçları Tablo 5'te verilmiştir. Palmitik asit oranı GEMO popülasyonunda \% 4.6 (GEMO-24) ile \% 9.2 (GEMO-18), GEW6'da \% 5.2 (GEW6-10) ile \% 10.1 (GEW6-6) ve GECE'de \% 6.2 (GECE-19) ile \% 8.6 (GECE-16) arasında değişirken, stearik asit oranı sirasiyla \% 1.5 (GEMO-19, 26, 27)-3.1 (GEMO-18), \% 1.8 (GEW6-6, 8, 12)-3.2 (GEW6-19) ve \% 1.8 (GECE14)-3.3 (GECE-2) arasında varyasyon göstermiştir. Oleik asit oranı en yüksek GEMO popülasyonunda \% 76.0 GEMO-3 ve 23 nolu hatlarda tespit edilmiş ve GEMO popülasyonunda \% 70'in üzerinde oleik asit içeren 3 adet hat belirlenmiștir. Ancak GEW6 populasyonunda 2 adet hat (GEW6-15 ve 18) \% 45-
60 arasında orta oleik asit grubunda yer aldığı görülmektedir. GECE hatlarının ana ve baba ebeveynleri yüksek linoleik tipi olduğu için popülasyonda bulunan hatlar yüksek linoleik asit içeriğine sahip olmuş ve ancak 6 hat (GECE-8, 9, 10, $12,18,19$ ve 20) kontrol genotiplerinden daha yüksek linoleik asit içeriği vermiştir. Yapılan araştırmalarda aspirde yağ asitleri bakımından oldukça geniş varyasyonlar elde edilmiștir. FernadezMartinez vd. [23] 37 ülkeden topladıkları 200 farklı aspir genotipinin oleik ve linoleik asit içerikleri önemli farklılıklar göstermiş ve bu yağ asitlerinin oranları sırasıyla \% 3.1-90.6 ve \% 3.9-88.8 arasında değiștiğini bildirmişlerdir. Valesco ve FernandezMartinez [27] ABD aspir koleksiyonundan 132 ekotipinde ortalama \% 5.8 palmitik asit (\% 3.4-10.2), $\% 2.2$ stearik asit (\% $0.8-9.9), \% 26.2$ oleik asit (\% 5.6-86.9) ve \% 65.9 linoleik asit (\% 7.1-88.7) içerdiğini belirlemişlerdir. Arslan ve Culpan [28] USDA (United States Department of Agriculture) koleksiyonundan 39 aspir genotipinde oleik asidin $\% 13.97-74.74$ ve linoleik asidin \%12.21-69.83 arasında değiştiğini bildirmişlerdir. Johnson vd. [24] tarafından 797 aspir introdüksiyon materyalinde palmitik asidin \% 3.9-6.8, stearik asidin \% 1.1-4.5, oleik asidin \% 6.2-81.9 ve linoleik asidin \% 11.0-83.1 arasında değiștiğini rapor etmișlerdir. Erbaș [13] 64 aspir hattında \% 5.43-9.18 palmitik asit, \% 1.98-4.15 stearik asit, \% 12.33-76.50 oleik asit ve \% 13.1775.06 linoleik asit varyasyonu olduğunu rapor etmiştir. Elde edilen sonuçlarımız yukarıda belirtilen araştırıcıların sonuçları ile uyum göstermiş ve belirtilen varyasyon sınırları içerisinde yer almıştır.

\section{Sonuç}

Sonuç olarak, 1000 tane ağırlığı, tohum verimi, yağ oranı ve yağ verimi özelliklerinin sırasıyla 30.2-51.0 g, $30.2-252.6 \mathrm{~kg} / \mathrm{da}$, \%25.1-35.4 ve $10.0-77.2 \mathrm{~kg} / \mathrm{da}$ arasında değiştiği görülmüştür. GECE-11 ve 12 nolu hatların 1000 tane ağırlığı, GEMO-10 ve 19 nolu hatlarin tohum verimi, GEMO-1, 20, 28, GEW6-16, 20 ve GECE-4, 8, 9, 12 nolu hatların yağ oranı, GEMO-10, 19,28 ve GEW6-20 nolu hatların ise yă verimi açısından ebeveynler ve diğer standart çeşitlere göre daha üstün oldukları tespit edilmiştir. 4 adet verim tipi (GECE-11, 12 ve GEMO-10,19), 11 adet yağ tipi (GEMO-1, 10, 19, 20, 28, GEW6-16, 20 ve GECE-4, 8, 9, 12), 2 adet oleik tipi (GEMO-3 ve GEMO-23), 1 adet linoleik tipi (GECE-7) olmak üzere toplam 15 hat bir sonraki generasyona aktarılmıștır.

\section{Teşekkür}

Bu çalıșma Ali ȘENATEȘ’in yüksek lisans tezinden türetilmiştir. Araştırmaya destek sağlayan (SDU BAP 4949-YL1-17) Süleyman Demirel Üniversitesi Bilimsel Araştırma Projeleri Koordinasyon Birimi'ne teşekkür ederiz. 
Tablo 5. Çeșitler ve hatların yağ asitleri kompozisyonu

\begin{tabular}{|c|c|c|c|c|c|c|c|c|c|c|c|c|c|c|}
\hline \multicolumn{15}{|c|}{ Çeșitler } \\
\hline & & \multicolumn{3}{|c|}{$C_{16: 0}$} & \multicolumn{5}{|c|}{$\mathrm{C}_{18: 0}$} & $\mathrm{C}_{18: 1}$ & & \multicolumn{3}{|c|}{$C_{18: 2}$} \\
\hline Dincer 5-18-1 & & \multicolumn{3}{|c|}{6.6} & \multicolumn{5}{|c|}{1.8} & 10.0 & & \multicolumn{3}{|c|}{81.2} \\
\hline W6 9822 & & \multicolumn{3}{|c|}{4.8} & \multicolumn{5}{|c|}{1.7} & 71.8 & & \multicolumn{3}{|c|}{21.2} \\
\hline Remzibey-05 & & \multicolumn{3}{|c|}{6.2} & \multicolumn{5}{|c|}{1.9} & 23.4 & & \multicolumn{3}{|c|}{68.1} \\
\hline Linas & & \multicolumn{3}{|c|}{5.8} & \multicolumn{5}{|c|}{2.1} & 39.2 & & \multicolumn{3}{|c|}{52.4} \\
\hline Olas & & \multicolumn{3}{|c|}{6.5} & \multicolumn{5}{|c|}{2.1} & 29.3 & & \multicolumn{3}{|c|}{61.5} \\
\hline Balcı & & \multicolumn{3}{|c|}{6.1} & \multicolumn{5}{|c|}{2.0} & 34.5 & & & 57.2 & \\
\hline Montola & & & 6.2 & & & 2. & & & & 69.2 & & & 21.9 & \\
\hline Gelendost-2 & & & 6.5 & & & 2. & & & & 11.6 & & & 78.9 & \\
\hline Centennial & & & 6.8 & & & 1. & & & & 11.3 & & & 79.7 & \\
\hline & & & & & & Hatle & & & & & & & & \\
\hline & GE & & & & & & W6 & & & & GE & & & \\
\hline Hat & $\mathrm{C}_{16: 0}$ & $\mathrm{C}_{18: 0}$ & $\mathrm{C}_{18: 1}$ & $\mathrm{C}_{18: 2}$ & Hat & $\mathrm{C}_{16: 0}$ & C18:0 & $\mathrm{C}_{18: 1}$ & $\mathrm{C}_{18: 2}$ & Hat & $\mathrm{C}_{16: 0}$ & $\mathrm{C}_{18: 0}$ & $\mathrm{C}_{18: 1}$ & $\mathrm{C}_{18: 2}$ \\
\hline GEMO-1 & 6.9 & 2.5 & 13.9 & 76.7 & GEW6-1 & 6.5 & 2.5 & 11.3 & 79.7 & GECE-1 & 7.7 & 2.6 & 10.7 & 79.0 \\
\hline GEMO-2 & 8.8 & 2.3 & 9.0 & 79.9 & GEW6-2 & 7.0 & 2.0 & 16.6 & 74.5 & GECE-2 & 7.2 & 3.3 & 10.6 & 78.9 \\
\hline GEMO-3 & 6.0 & 2.4 & 76.0 & 15.7 & GEW6-3 & 7.1 & 2.3 & 21.4 & 69.3 & GECE-3 & 7.7 & 2.8 & 10.9 & 78.7 \\
\hline GEMO-4 & 6.3 & 2.2 & 26.1 & 66.0 & GEW6-4 & 6.5 & 2.7 & 25.8 & 62.2 & GECE-4 & 6.7 & 2.2 & 10.0 & 81.1 \\
\hline GEMO-5 & 6.4 & 2.1 & 10.5 & 81.0 & GEW6-5 & 5.8 & 1.9 & 15.3 & 74.7 & GECE-5 & 7.1 & 2.1 & 11.2 & 79.6 \\
\hline GEMO-6 & 7.4 & 2.1 & 15.2 & 75.3 & GEW6-6 & 10.1 & 1.8 & 8.9 & 79.1 & GECE-6 & 7.3 & 2.2 & 10.7 & 79.8 \\
\hline GEMO-7 & 6.3 & 2.2 & 9.0 & 82.5 & GEW6-7 & 9.5 & 2.0 & 11.5 & 77.0 & GECE-7 & 7.1 & 2.4 & 10.3 & 80.2 \\
\hline GEMO-8 & 7.5 & 2.6 & 8.8 & 81.1 & GEW6-8 & 6.4 & 1.8 & 16.5 & 75.3 & GECE-8 & 6.3 & 1.9 & 9.1 & 82.7 \\
\hline GEMO-9 & 8.2 & 2.1 & 9.8 & 79.9 & GEW6-9 & 10.0 & 2.0 & 10.3 & 77.6 & GECE-9 & 6.8 & 2.5 & 9.3 & 81.4 \\
\hline GEMO-10 & 6.9 & 2.1 & 20.5 & 71.0 & GEW6-10 & 5.2 & 2.4 & 11.8 & 77.8 & GECE-10 & 7.0 & 2.1 & 9.4 & 81.5 \\
\hline GEMO-11 & 6.1 & 1.9 & 8.8 & 83.2 & GEW6-11 & 6.9 & 2.6 & 9.8 & 73.4 & GECE-11 & 6.3 & 2.9 & 11.1 & 79.7 \\
\hline GEMO-12 & 7.9 & 2.2 & 10.4 & 79.5 & GEW6-12 & 5.5 & 1.8 & 10.9 & 79.3 & GECE-12 & 6.6 & 2.4 & 9.0 & 81.9 \\
\hline GEMO-13 & 6.5 & 2.3 & 14.2 & 74.8 & GEW6-13 & 7.3 & 2.1 & 10.7 & 79.9 & GECE-13 & 6.8 & 2.0 & 10.2 & 81.0 \\
\hline GEMO-14 & 8.7 & 2.0 & 8.7 & 80.6 & GEW6-14 & 7.9 & 3.2 & 13.2 & 73.8 & GECE-14 & 7.2 & 1.8 & 9.9 & 81.2 \\
\hline GEMO-15 & 7.6 & 2.1 & 10.5 & 79.8 & GEW6-15 & 5.8 & 0.7 & 45.7 & 47.7 & GECE-15 & 7.5 & 2.2 & 9.7 & 80.7 \\
\hline GEMO-16 & 7.4 & 2.3 & 9.6 & 80.7 & GEW6-16 & 6.5 & 2.3 & 10.8 & 79.6 & GECE-16 & 8.6 & 2.2 & 8.8 & 80.4 \\
\hline GEMO-17 & 7.9 & 2.0 & 9.0 & 81.1 & GEW6-17 & 6.9 & 2.2 & 8.7 & 82.2 & GECE-17 & 6.5 & 2.3 & 10.4 & 80.8 \\
\hline GEMO-18 & 9.2 & 3.1 & 9.8 & 77.9 & GEW6-18 & 7.4 & 1.9 & 58.7 & 32.0 & GECE-18 & 6.9 & 2.2 & 9.6 & 81.3 \\
\hline GEMO-19 & 5.3 & 1.5 & 65.7 & 27.4 & GEW6-19 & 7.3 & 3.2 & 9.6 & 79.9 & GECE-19 & 6.2 & 2.2 & 9.1 & 82.5 \\
\hline GEMO-20 & 6.8 & 2.8 & 13.4 & 77.1 & GEW6-20 & 6.5 & 2.6 & 9.0 & 81.9 & GECE-20 & 6.6 & 2.3 & 9.2 & 81.9 \\
\hline GEMO-21 & 6.2 & 2.3 & 30.5 & 61.1 & & & & & & & & & & \\
\hline GEMO-22 & 6.7 & 2.2 & 10.4 & 80.7 & & & & & & & & & & \\
\hline GEMO-23 & 4.9 & 2.0 & 76.0 & 17.1 & & & & & & & & & & \\
\hline GEMO-24 & 4.6 & 2.3 & 74.2 & 18.9 & & & & & & & & & & \\
\hline GEMO-25 & 6.2 & 1.7 & 30.8 & 61.3 & & & & & & & & & & \\
\hline GEMO-26 & 7.9 & 1.5 & 7.3 & 83.3 & & & & & & & & & & \\
\hline GEMO-27 & 5.4 & 1.5 & 7.9 & 79.6 & & & & & & & & & & \\
\hline GEMO-28 & 6.2 & 2.8 & 30.8 & 60.3 & & & & & & & & & & \\
\hline
\end{tabular}

\section{Kaynakça}

[1] Anonim, 2019a. http://www.bysd.org.tr/Dis TicaretRakamlari/(Erişim tarihi: 20.06.2019).

[2] Erbaş, S., Baydar, H. 2007. Aspirde (Carthamus tinctorius L.) Sentetik Erkek Kısırlık Tekniği ile Elde Edilmiş Melez Popülasyonlardan Hat Geliştirme Olanakları, 7. Tarla Bitkileri Kongresi, 25-27 Haziran, Erzurum, 370-374.

[3] Emongor, V.E., Oarabil, P., Phuduhudud, O. 2017. Effects of Genotype on Vegetative Growth, Yield Components and Yield, Oil Content and Oil Yield of Safflower. Agricultural Science Research Journal, 7(12), 381-392.

[4] Baydar, H., Erbaş, S. 2016. Aspir (Carthamus tinctorius L.)'de Verim, Yağ ve Oleik Asit İçeriği Yüksek Hat Geliştirme Islahı Tarla Bitkileri Merkez Araştırma Enstitüsü Dergisi, 25 (Özel sayl-2), 155-161.
[5] Rowell, D.L. 1996. Soil Science: Methods and Applications. Longman. London.

[6] AOAC, 2005. Official method of Analysis. 18 Edition, Association of Officiating Analytical Chemists, Washington DC.

[7] SAS Institute. 1998. INC SAS/STAT User's Guide Release 7.0, Cary, NC, USA.

[8] Anonim, 2019b. Meteoroloji Genel Müdürlüğü.

[9] Weiss, E.A., 2000. Oilseed Crops, (2nd Edition), Blackwell Sci. Ltd., Victoria, Australia.

[10] Pahlavani, M.H., Saeidi, G., Mirlohi, A.F. 2007. Genetic Analysis of Seed Yield and Oil Content in Safflower Using $F_{1}$ and $F_{2}$ Progenies of Diallel Crosses. International Journal of Plant Production, 2, 129-140. 
[11] Ramachandram, M., Goud, J.V. 1981. Genetic Analysis of Seed Yield, Oil Content and Their Components in Safflower (Carthamus tinctorius L.) Theor. Appl. Genet., 60, 191-195.

[12] Alizadeh, K. 2005. Evaluation of Safflower Germplasm by Some Agronomic Characteristics and Their Relationships on Grain Yield Production in the Cold Dry Land of Iran. International Journal of Agriculture \& Biology, 7(3), 389-391.

[13] Polat, T. 2007. Farklı sıra aralıklarının ve azot seviyelerinin kuru şartlarda yetiştirilen aspir (Carthamus tinctorius L.) bitkisinin verim ve verim unsurları üzerine etkisi. Atatürk Üniversitesi, Fen Bilimleri Enstitüsü, Doktora Tezi, 155s, Erzurum.

[14] Paşa, C., Esendal, E., Arslan, B. 2009. Kışlık ve Yazlık Ekimin Aspir (Carthamus tinctorius L.) Bitkisinin Verimi ve Bitkisel Özelliklerine Etkisi Türkiye VIII. Tarla Bitkileri Kongresi, 19-22 Ekim, Hatay, 168-171.

[15] Erbaş, S. 2012. Melezleme islahı ile tohum verimi, yağ ve oleik asit içeriği yüksek aspir (Carthamus tinctorius L.) hatlarının geliștirilmesi. Süleyman Demirel Üniversitesi, Fen Bilimleri Enstitüsü, Doktora Tezi, 132s, Isparta.

[16] Reddy, M.V.S., Chand, P., Vidyadhar, B., Devi, I.S.L. 2004. Estimation of Genetic Parameters for Yield and Its Component in $\mathrm{F}_{4}$ Generation of Safflower (Carthamus tinctorius L.). Prog. Agric., 4(1), 16-18.

[17] Erbaş, S. 2007. Aspirde (Carthamus tinctorius L.) sentetik erkek kısırlığı tekniği ile elde edilmiş melez populasyonlarından hat geliștirme olanakları. Süleyman Demirel Üniversitesi, Fen Bilimleri Enstitüsü, Yüksek Lisans Tezi, 94s, Isparta.

[18] Safevi, S.A., Pourdad, S.S., Safavi, S.M., Safavi, A.S. 2011. Heritability and Genetic Gain of Some Morphological Traits in Safflower (Carthamus tinctorius L.). American Journal of Scientific Research, 17, 14-18.

[19] Çelikoğlu, F. 2004. Eskişehir Koşullarında Geliştirilen Aspir (Carthamus tinctorius L.) Hatlarında Verim Kriterlerinin Belirlenmesi.
Ankara Üniversitesi, Fen Bilimleri Enstitüsü, Yüksek Lisans Tezi, 76s, Ankara.

[20] Lakshmi Prayaga, P., Lakshmamma, P., Padmavthi, P., 2003. Characterization of Safflower Germplasm for Physiological Traits. Sesame and Safflower Newsletter, 18, 90-92.

[21] Parameshwar, K.B. 2009. Stability of Non-Spiny Breeding Lines in Safflower (Carthamus tinctorius L.). Dharwad University of Agricultural Sciences, Master Thesis, 92s, India.

[22] Arslan, B., Culpan, E. 2017. Effects of Different Gibberellic Acid Doses on Seed Yield, Oil Content and Some Quality Traits of Safflower (Carthamus tinctorius L.). Journal of Global Innovations in Agricultural and Social Sciences, 5(1), 5-9.

[23] Fernandez-Martinez, J., Del Rio, M., De Haro, A. 1993. Survey of Safflower (Carthamus tinctorius L.) Germplasm for Variants in Fatty Acid Composition and Seed Characters. Euphytica, 69, 115-122.

[24] Johnson, R.C., Bergman, J.W., Flynn, C.R. 1999. Oil and Meal Characteristics of Core and Non-Core Safflower Accessions from the USDA Collection. Genet. Res. Crop Evol., 46, 611-618.

[25] Erbaş, S., Tonguç, M., Şanll, A. 2016. Variations in the Agronomic and Quality Characteristics of Domestic and Foreign Safflower (Carthamus tinctorius L.) Genotypes. Turk J. Field Crops, 21(1), 110-119.

[26] Kıllı, F., Ermiş, H. 2009. Kahramanmaraş Koşullarında Farklı Miktarlarda ve Zamanlarda Uygulanan Azotun Aspir (Carthamus tinctorius L.)'de Tohum Verimi, Verim Unsurları ve Tohumun Makro-Mikro Element İçeriğine Etkisi. Türkiye VIII. Tarla Bitkileri Kongresi, 19-22 Ekim, Hatay, 107-110.

[27] Valesco, L., Fernandez-Martinez, J.M. 1999. Screening for Low Saturated Fatty Acids in Safflower. Sesame and Safflower Newsletter, Cordoba, Spain.

[28] Arslan, B., Culpan, E. 2018. Identification of Suitable Safflower Genotypes for the Development of New Cultivars with High Seed Yield, Oil Content and Oil Quality. Azarian Journal of Agriculture, 5 (5), 133-141. 